\title{
A Short Surface Pathway of the Subsurface Indonesian Throughflow Water from the Java Coast Associated with Upwelling, Ekman Transport, and Subduction
}

\author{
Vinu Valsala and Shamil Maksyutov \\ GOSAT, CGER, National Institute for Environmental Studies, Tsukuba, Ibaraki 305-8506, Japan \\ Correspondence should be addressed to Vinu Valsala, vinu.valsala@nies.go.jp \\ Received 26 August 2010; Accepted 18 November 2010 \\ Academic Editor: Grant Bigg
}

Copyright ( 2010 V. Valsala and S. Maksyutov. This is an open access article distributed under the Creative Commons Attribution License, which permits unrestricted use, distribution, and reproduction in any medium, provided the original work is properly cited.

A surface pathway of the subsurface Indonesian Throughflow (ITF) in the southeastern Indian Ocean is proposed using a combined analysis of Lagrangian particles and passive tracers derived from two independent tools: an Ocean General Circulation Model (OGCM) and Simple Ocean Data Assimilation (SODA.2.0.2) reanalysis data. This newly suggested pathway follows the processes in succession as upwelling in the south Java coast, offshore Ekman drift and subduction into the thermocline centered on $20^{\circ} \mathrm{S}$. The upwelling of subsurface ITF along the south Java coast is found to occur from August to October. Upon surfacing, the ITF advects southwestward being trapped in the surface Ekman layer for an approximate period of 260 days and reaches the southeastern tropical Indian Ocean subduction zone centered on $20^{\circ} \mathrm{S}$ which is demarcated by the Zero Wind Stress Curl (ZWSC) and subducts there. The particle trajectory revealed that during the subduction within the ZWSC region, the surface eastward flow above $120 \mathrm{~m}$ depth carries the particle about $10^{\circ}$ to the east and westward flow below this depth carries the particle to the western Indian Ocean along the thermocline. These pathways are confirmed by a series of tracer experiments using SODA reanalysis data. The effects of vertical mixing and entrainment on the surfacing of the ITF at south Java coast were identified.

\section{Introduction}

The Indonesian Throughflow (ITF) is a system of currents flowing from the Pacific to the Indian Ocean via the Indonesian Straits. It is a well-established fact that the ITF has a significant control on the global oceanic heat budget as well as the regional air-sea heat fluxes of the Indian Ocean $[1-5]$. This interoceanic flow carries nearly a $10-15 \mathrm{~Sv}(1 \mathrm{~Sv}=$ $10^{6} \mathrm{~m}^{3} \mathrm{~s}^{-1}$ ) of Pacific water, which is mostly composed of low saline North Pacific upper thermocline water and high saline lower thermocline Indonesian Sea water, to the tropical Indian Ocean [2]. The lowest estimate of $10 \mathrm{~Sv}$ is only a general agreement attained from very limited current mooring observations (which were actually carried out when El Niño of 1997 was suppressing the ITF; [6]) in the key channels of the ITF entrance region. The precise measurements of the total ITF volume transport are still underway and new estimates are appearing in the literature recently [7-9]. For instance, the moorings deployed between
2004 and 2006 suggest that the ITF volume transport can be as large as $15 \mathrm{~Sv}[7,9]$. In this paper, we use the name "exit region" in order to refer to the Indonesian Island regions and the immediate southeastern Indian Ocean where the ITF exits to the Indian Ocean. The ITF water mass mixes with the Indian Ocean waters and cools in the exit region and releases large amount of heat which can amount up to $50 \%$ of the total austral winter cooling existing over the offnorthwestern coast of Australia [10].

Previous studies examined the large-scale 3-dimensional climatological pathways of the ITF in the Indian Ocean using combined set of tools, such as the Lagrangian particles, passive tracers and active tracers (temperature and salinity) [10-13]. In particular, Valsala and Ikeda [10] found that the ITF, from its exit region to the western tropical Indian Ocean, has two major pathways: (1) a surface branch that advects along the Leeuwin current system and subducts offnorthwestern coast of Australia and flows northwestward along the thermocline depth, and (2) a subsurface branch 
that departs directly from the exit region of the Indonesian Islands to the western Indian Ocean along the thermocline depths between $15^{\circ} \mathrm{S} \sim 25^{\circ} \mathrm{S}$. Upon reaching the western boundary of the Indian Ocean, about $70 \%$ of the ITF turns to the northern Indian Ocean and the remaining portion turns to the south. Among the northward turning parts of ITF, 26\% travels across the Indian Ocean from west to east along the south of the equator at a depth of $200 \mathrm{~m}-300 \mathrm{~m}$. Another $24 \%$ travels across the Indian Ocean from west to east along the north of the equator at a depth of $100 \mathrm{~m}-200 \mathrm{~m}$. The remaining part surfaces via upwelling in the Somali and Arabian coasts and spreads all over the surface Indian Ocean. The schematic picture shown in Figure 15 of Valsala and Ikeda [10], summarizes these pathways as resolved from the Lagrangian trajectories and passive tracers employed in the previous studies.

In addition to the above-mentioned two major pathways, another pathway of ITF may exist in the exit region, as suggested from the regional wind stress field. The boreal summer monsoon winds over Indonesian Seas are southeasterlies and are favorable for upwelling along the south Java coast. A strong wind stress-core associated with the southeasterly trade winds migrates northwestward along south Java-Sumatra coast from June to September [14]. The coastal upwelling of Java-Sumatra is shown to follow this wind stress-core migration. In the later part of September, the upwelling collapses as the southeasterly trade winds weaken and the Java coast experiences weak northwesterly winds $[14,15]$. Thus, a pathway of ITF in the exit region in response to the local wind stress and upwelling could exist. A hint to the existence of such a short living pathway of the ITF in the exit region is reported in Figure 8(e) of Valsala and Ikeda [10]. In that work, it was noted that the subsurface passive tracer, which was initialized below a depth of $150 \mathrm{~m}$ in order to represent the subsurface ITF, upwelled at the Java coast during boreal summer and spread over the surface. However, a detailed examination of this pathway was not done in the previous study, where the focus was on an exhaustive description of major and basin-wide spreading of ITF in the Indian Ocean. Therefore, in this study, we examine this rather short, while important, part of the ITF pathway in the exit region.

The importance of upwelling of the ITF in the exit region can be revealed from its possible impacts on the local SST development. Unlike the other eastern boundaries of the world oceans, the southeastern Indian Ocean is unique in its absence of a cold SST due to local upwelling (e.g., cold SST tongues observed in the eastern equatorial Pacific and Atlantic [16]). Du et al. [17] suggested that the southeastern Indian Ocean has a different regional thermodynamic cycle. The south Java zone is characterized by the presence of warm ITF advection which mitigates the SST cooling due to the local upwelling [17]. The authors concluded that the horizontal advection of the ITF is a major reason for the mixed layer warming seen in the south Java coast. The observations made from current meters moored at the Java coast suggest that the arrival of Kelvin wave originating from the equatorial Indian Ocean causes a warming of water column in the south Java coast. Following the wave passage, the coastal currents along south Java are north-westward and the prevailing southeasterly monsoon winds lead to upwelling of salty subsurface water [18].

The previous studies showed that not only the advection but also the upwelling can bring the ITF to the surface at south Java coast [10]. Considering the fact that the subsurface ITF is warmer than the thermocline Indian Ocean waters $[12,19]$, its upwelling at the south Java coast may also have impact on the local SST development. Thus, the upwelling of ITF along south Java coast is an important factor for a further investigation. In addition, there is no question that this region is in a key region for climate variations in the Indo-Pacific sector where the eastern pole the Indian Ocean Dipole/Zonal Mode (IODZM) starts to develop [20, 21]. Valsala et al. [22] found a close correlation between the IODZM and ITF interannual pathway variability. The internal seas in this region represent a "cross-road" of wave guides as several waves from the Pacific Ocean, Indonesian seas and Indian Ocean meet in this area $[23,24]$.

A direct estimation of upwelling of ITF at the south Java coast from the observations, however, is a tedious task. At the first place the direct observations of Java-Sumatra coastal currents are limited. The WOCE observation tracks did not cover Java-Sumatra coast well, especially the south Java shelf region. A strong semiannual South Java Current (SJC) was observed from one year mooring record [18]. Recently Sprintall et al. [8] updated the SJC and South Java Under Current (SJUC) as they were inferred from the current moorings situated at Ombai Strait. According to these previous studies, the south Java shelf circulation has following seasonality. An eastward flowing SJC exists from surface to $120 \mathrm{~m}$ and almost throughout the year. The SJUC flows westward below this depth. A weak eastward flow around $600 \mathrm{~m}$ is observed during April and October. A climatological chart of geostrophic currents in the southeastern Indian Ocean was recently compiled by Qu and Meyers [25] and updated by Wuffels et al. [26]. Upwelling in the south Java coast may bring both the Indian Ocean water of the exit region as well as the ITF water to the surface. Thus separating these two components becomes difficult from the limited observations of temperature, salinity or any other biogeochemical tracer. In this study, we achieve this goal by a set of tracer experiments employed in an OGCM and also in a reanalysis data set.

The rest of the paper has following structure. A brief description of the OGCM and methods are given in Section 2. The southern Java upwelling of the ITF identified from particle trajectories and tracers are given in Section 3, followed by a comparison of the pathways by analyzing ocean reanalysis data set and tracer experiments in Section 4. The volume transport is shown in Section 5. The results and uncertainties are discussed in Section 6.

\section{OGCM and Methods}

This study uses an OGCM known as Australian Community Ocean Model.2 (ACOM.2) which is a slightly modified version of Modular Ocean Model.2 (MOM.2) [27]. The model 
setup is common as given in [10]. The model domain includes both the Indian Ocean and Pacific Ocean $\left(0^{\circ}-\right.$ $\left.290^{\circ} \mathrm{E}, 40^{\circ} \mathrm{N}-65^{\circ} \mathrm{S}\right)$. An east-west cyclic boundary is applied between $55^{\circ} \mathrm{S}-65^{\circ} \mathrm{S}$, in order to regulate the strength of Antarctic Circumpolar Current (ACC) nearly by 65 Sv (south of $45^{\circ} \mathrm{S}$ ) and thus the interior model solution of the Indian Ocean is not strongly affected by the boundaries. Horizontal viscosity and diffusion coefficients for temperature, salinity and passive tracers are kept constants as $4.0 \times 10^{3}$ and $2.0 \times$ $10^{3} \mathrm{~m}^{2} \mathrm{~s}^{-1}$, respectively. Vertical mixing is parameterized using the method of Chen et al. [28]. Shortwave flux is prescribed from Josey et al. [29]. Latent heat flux is estimated from the model SST using bulk parameterizations with a prescribed humidity ratio from da Silva et al. [30].

The model has a zonal resolution of $1^{\circ}$ and a meridional resolution of $0.5^{\circ}$. With this resolution the upwelling may not be resolved completely in the model. Considering the orientation of the south Java coast which runs nearly in an east-west direction, a $0.5^{\circ}$ of meridional resolution (i.e., nearly $55 \mathrm{~km}$ ) is responsible for resolving the coastal upwelling. The magnitude of wind-driven coastal upwelling weakens exponentially from the coast within a distance of local Rossby radius of deformation which is nearly 30 $50 \mathrm{~km}$ for first two baroclinic modes. Therefore, the winddriven coastal upwelling in the model employed here may suffer from a reduced intensity than that found in the real world. However, the model vertical velocities have shown an upwelling pattern along the south Java coast that is consistent with what the coastal wind suggests. The model has a total of 25 vertical levels with first 16 levels in the upper $300 \mathrm{~m}$. The vertical resolution was kept as $15 \mathrm{~m}$ until the upper $150 \mathrm{~m}$ depth of the ocean and stretched vertical resolution is employed thereafter. The model does not account for tideinduced mixing in the coasts.

Two channels, Lombok strait with 400-m depth and Timor strait with $1100-\mathrm{m}$ depth, permit the ITF to enter the Indian Ocean in the model. The Ombai channel was considered as coalesced with Timor channel due to limitations in resolving the topography with the given model resolution. In reality, the sill depth of Timor strait is $1250 \mathrm{~m}$ and that of the Lombok strait is $300 \mathrm{~m}$. The effects of small differences between the model sill depths and that in the real world are, however, minor in the total ITF resolved above $300 \mathrm{~m}$ in the model. The throughflow is permitted through the Makassar Strait, Banda Seas, and Java seas. Papua New Guinea is connected to Australia and Torres Strait is closed. The model annual mean volume transport over the upper $300 \mathrm{~m}$ of Timor strait is nearly $6 \mathrm{~Sv}$ and that of Lombok strait is $4 \mathrm{~Sv}$ with a total of $10 \mathrm{~Sv}$ of ITF to the Indian Ocean. The seasonal cycle of the model Lombok flow has following features. A maximum transport was obtained during September and a minimum during January to March. Throughout the year the Lombok flow was toward the Indian Ocean. The corresponding seasonal cycle of Timor flow has a maximum transport during July. The eastern side of the model Timor strait has shown a weak flow northward and away from the Indian Ocean. The model Timor flow has a weak semiannual cycle. The total ITF into the Indian Ocean in the model has maximum amplitude of $13 \mathrm{~Sv}$ during
August [10] which is consistent with the recent observations [6].

The model was spun up for 20 years using climatological seasonal winds from Hellerman and Rosenstein [31]. The climatological simulations of the model are analyzed from a 5 year average constructed from the spinup point. The details of model solutions and validation are given in [10].

In order to find out the pathways of the ITF related to the south Java upwelling we used both forward and backward Lagrangian particle trajectories starting from a region offsouth Java coast. The trajectories are derived from the 3Dimensional monthly mean model velocities interpolated linearly into a time step of 900 seconds. Such an interpolation scheme applied on the velocities may, arguably, results in a smoothed trajectory of individual particles with little representation of sporadic changes in the ocean dynamics. However, the focus of the present study is to look at the seasonal dynamics of Lagrangian particles which is well resolved with the velocities interpolated from a monthly model output. The choice of 900 seconds was made in order to match the time step to the one used for our OGCM integration. Moreover, we compared the Lagrangian trajectories derived from the online model with our offline trajectories in order to make sure the usage of the offline currents does not affect the trajectories compared to its online counterpart. Because of the monthly climatological forcing used in the model simulations, the Lagrangian trajectories derived from both the online and the offline models were similar.

Lagrangian particles do not include either horizontal diffusion or vertical mixing but represent the horizontal advection and vertical motion due to upwelling or subduction. In order to assess the effect of mixing and diffusion, we additionally used passive tracers which were initialized in the Indonesian sea region.

The particles for forward and backward trajectories were initialized over a box extending from $95^{\circ} \mathrm{E}-105^{\circ} \mathrm{E}, 16^{\circ} \mathrm{S}-8^{\circ} \mathrm{S}$, and $0-50 \mathrm{~m} .10,000$ particles were distributed uniformly in the above box. The tracers were released in the Indonesian sea region over a box of $110^{\circ} \mathrm{E}-140^{\circ} \mathrm{E}, 20^{\circ} \mathrm{S}-10^{\circ} \mathrm{N}$ and surface to ocean floor. Six passive tracers were released from the surface to the bottom (i.e., Tracer- 1 in the surface and Tracer- 6 at the bottom) with an approximate vertical thickness of $60 \mathrm{~m}$ for each tracer except for the Tracer- 6 which was initialized unto the ocean floor. Although we released 6 tracers here, we discuss results from only the relevant tracers in order to avoid redundancy. A detailed difference between spreading of each of these tracers can be found in [10]. Unlike the Lagrangian particle trajectories, the tracers were integrated online along with the complete model equations, and hence they undergo vertical mixing and horizontal diffusion. Thus, the tracers provide a complementary analysis to the Lagrangian particles. We run the tracer experiments for 10 years.

In order to verify the pathways resolved in our OGCM, we examined the ocean reanalysis data set derived from Simple Ocean Data Assimilation (SODA 2.0.2) prepared by Carton and Giese [32]. The method of verification was also based on a set of tracer experiments but carried out with 
the SODA data circulation and other physical parameters. The SODA circulations, temperature, salinity, and other physical parameters were used in an offline model in order to evolve a passive tracer. In this case, we used the offline Ocean Tracer Transport Model (OTTM) as described in [33]. OTTM has self-operating diagnostic mode vertical mixing and subgrid-scale processes parameterization schemes, because the coefficients for these processes were not readily available from the reanalysis data. They were estimated within the OTTM. Vertical mixing was represented as a combination of the K-Profile Parameterization (KPP; Large et al., 1994) and a background vertical diffusion suggested by Bryan and Lewis [34]. Horizontal diffusions were calculated as a combination of flow-dependent diffusion in which the coefficients are proportional to the stress and strain experienced in the local fluid volume [35] and advection fluxes due to eddy-induced transports [36].

The data for horizontal advection was taken from the offline data archive, whereas vertical velocities were calculated based on the mass conservation principles. The free-surface kinematic boundary condition was determined from the sea surface height. OTTM-derived transports were extensively tested via simulating Chlorofluorocarbon and were documented in [33]. Further details of the model design and validation can be found there. The exaggerated vertical mixing of OTTM found in the tropics as reported in the work of Valsala et al. [33] was resolved by further tuning of the model in the present study.

The usage of offline model driven by a reanalysis ocean data set enabled us to set up various tracer experiments in order to resolve particular upwelling pathway of the ITF from the south Java coast. An additional advantage is that the SODA.2.0.2 circulations are originally designed in $0.25^{\circ} \times 0.4^{\circ}$ resolution in longitude and latitude and likely to represent the coastal upwelling and topography of Indonesian straits more realistically than our rather coarse resolution OGCM. Therefore, the side-by-side analysis of SODA data can be justified as an evaluation for our OGCM results.

SODA is an ocean reanalysis product widely used to evaluate the upper ocean climate change in the past five decades. This data set is made from the Parallel Ocean Program (POP) configuration of Modular Ocean Model (MOM) with a sequential update of approximately 710 observational profiles of temperature and salinity from the World Ocean Database [16] and the US National Oceanic and Atmospheric Administration/National Oceanic Data Center archives. In addition to the historic and time-series observations of temperature and salinity, the observations from a number of Argo profiles since early 2000 are also incorporated into the SODA system. More details of the model configuration and design can be found in [32].

In this study the SODA.2.0.2 with a subsampled resolution of $0.5^{\circ} \times 0.5^{\circ} \times 40^{\circ}$ levels is used which is available for the public use. Among the 40 vertical levels the first 20 levels are above the depth of $579 \mathrm{~m}$. The monthly SODA data are interpolated into a model time step of 2-hours. Here, we note that our focus in this study is only the seasonal pathways of the ITF.

\section{Upwelling of ITF in South Java Coast}

The analysis of the ITF trajectories resolved in our OGCM shows that subsurface tracer, which was initialized below a depth of $160 \mathrm{~m}$ in the Indonesian seas, appeared in the surface by following the seasonal upwelling along the south Java coast during the boreal summer (Figure 1). Tracer-3 (black contours), which was initialized at a depth of 164.8$224.1 \mathrm{~m}$ in the model appeared in the surface after a few years of the simulation. This implies that the subsurface ITF is advected along the south Java coast and then upwelled and appeared in the surface.

In order to illustrate this upwelling, we tracked Lagrangian trajectories forward and backward from a region of offsouth Java coast (see Section 2). The particles are initialized over a depth of $0-50 \mathrm{~m}$ in the south Java-Sumatra coast and integrated both forward and backward in time. Figure 1 shows the backward trajectory of a selected particle from the group (solid color-line) with each segment of color representing each month of the trajectory. It can be seen that the backward trajectory extends to the southern Java coast exactly at the core of the upwelling zone shown by the Tracer-3. The particle in the backward trajectory, on the other hand, traveled further deep to a depth of $100 \mathrm{~m}$ and gradually stretched back to the Lombok Strait. The vertical trajectory of this particular particle reveals that the particle traveled from the point of origin to the south Java coast in two months (December and November) and then followed a steep vertical motion in October, September and August (Figure 1(b)). The position of the particle at the beginning of August is nearly $105 \mathrm{~m}$ and within the vicinity of Lombok strait. Thus, it is evident that the model solutions support a partial upwelling of the ITF in the Java coast, especially from the Lombok throughflow during the boreal summer.

It was noted in previous studies that the upwelling center of the south Java coast migrates northwestward along the coast by following the seasonal migration of alongshore winds [14]. The standard deviation maps of monthly SST at the Java-Sumatra coast show that the upwelling begins at the center of southern Java coast in June and then migrates northwestward and reaches Sumatra coast by September [14]. The backward trajectory shown in our OGCM also predicts an upwelling which is prominent during the month of August to September. This is consistent with the SST deviation maps of Susanto et al. [14]. After upwelling, the particle followed a path southwestward as it was trapped in the surface Ekman layer. The direction of this off-shore Ekman drift is almost normal to the south Java coast.

The same particle was tracked forward in time from the same point of origin. The resultant forward trajectory of this particle is shown as "+" symbols in Figure 1(b). The forward trajectory continued in the same direction for half a year time period and reached at a location of $88^{\circ} \mathrm{E}, 20^{\circ} \mathrm{S}$ without much deviation in its vertical position (Figure 1(b)). Thus, the surface Ekman transport caused the upwelled ITF to advect southwestward. The speed of the Ekman transport is stronger near the coast and weaker in the open ocean. This shows the Ekman convergence in the open ocean due to the trade winds in the tropics and westerlies in the subtropics. 

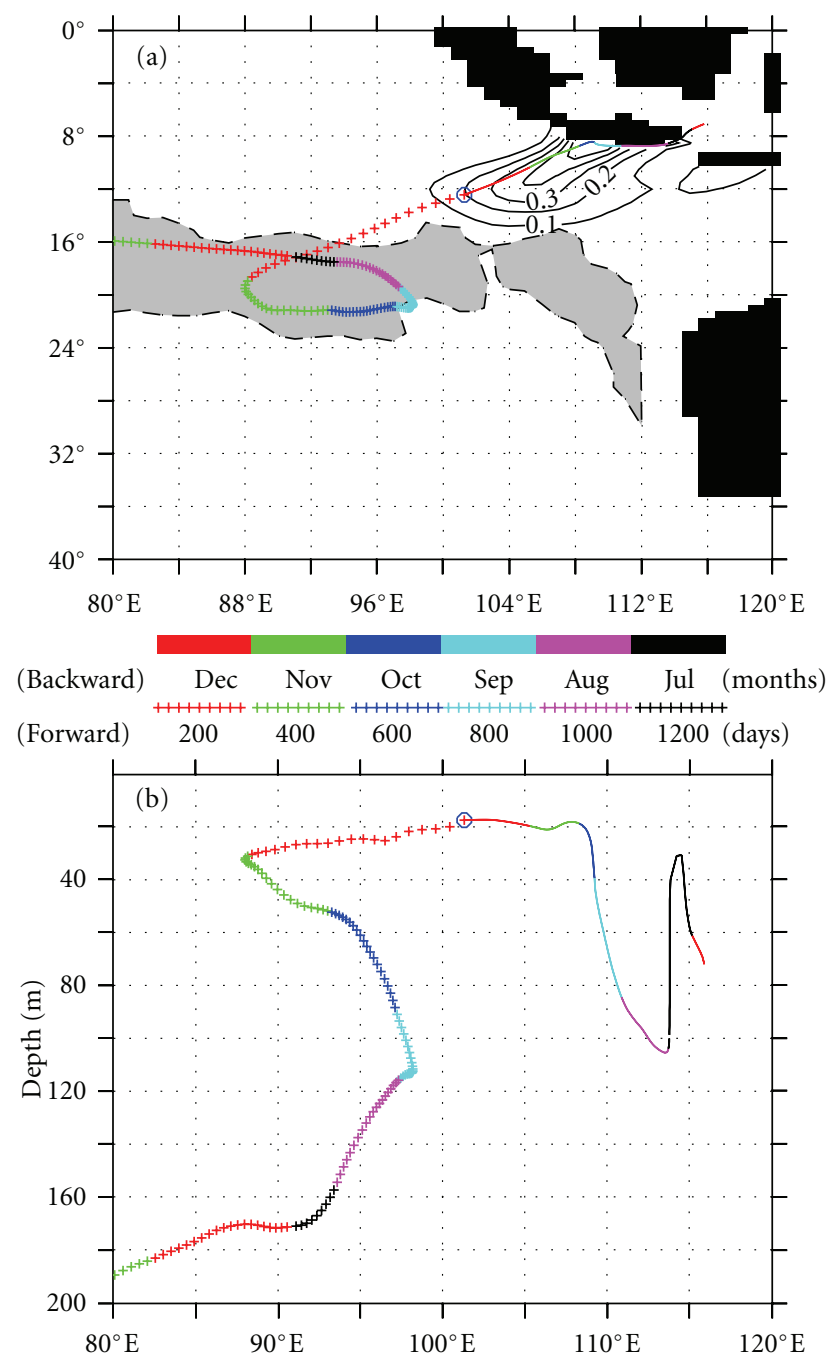

Figure 1: Backward (color line) and forward (“+” symbol) particle trajectories initialized at $20 \mathrm{~m}$ are shown in the (a) plan view and (b) the vertical section. Different color key is used for the forward and backward trajectories. The black solid contours in (a) represent the concentrations of Tracer-3 on the model surface level after two years of integration (units are in concentration per $\mathrm{m}^{-3}$ ). The shaded area represents the seasonal march of Zero Wind Stress Curl (ZWSC) line with its extreme southern position for January and the extreme northern position for August.

After reaching nearly $20^{\circ} \mathrm{S}$, the particle subducted there. The subduction is also shown in the vertical section in Figure 1(b). The simultaneous subduction and anticyclonic trajectory in the horizontal plane caused the particle to wander for 1200 days in the analysis region. The subduction was accompanied by a clear anticyclonic trajectory as shown in the plan view of Figure 1(a).

The subduction requires a forcing either as a vertical Ekman pumping or as a horizontal transport which hits the base of the mixed layer [37]. Here, the position where the particle sinks to the subsurface was within the zone of seasonal excursions of Zero Wind Stress Curl (ZWSC) where the Ekman convergence is maximum. The shaded region in
Figure 1(a) corresponds to the monthly mean locations of ZWSC as calculated from the Hellerman and Rosenstein [31] wind stress data. The southernmost part of the shaded region delineates the location of ZWSC in the month of January while the northernmost part delineates its corresponding location in the month of August. The particle trajectory clearly shows a subduction within the excursion limit of ZWSC. Thus, the surface forcing by Ekman pumping causes the particle to sink to the subsurface in this zone. After the subduction these particles merge with the thermocline pathways of the ITF and flow northwestward. The upwelling pathway of the ITF from south Java coast takes nearly 260 days from the Java coast to the subduction zone.

The subduction in the open ocean was also a feature of more complete trajectories of those particles which were originally driven from the ITF exit region and cross the equator northward near the western boundary (African continent). These particles undergo upwelling at various positions in the northern Indian Ocean and cross the equator southward via a shallow equatorial roll and reach this subduction zone at $20^{\circ} \mathrm{S}$ and subducts by following an anticyclonic deepening pathway (see [10] and their Figure 3). In the present study, on the other hand, we have found an immediate subduction of particles just after the upwelling at the south Java coast. This particular pathway can be considered as the shortest surface pathway of the subsurface ITF in the exit region. The possibilities of such pathways are mentioned in the review of Schott et al. [38], but there are no previous studies which illustrated this particular pathway.

An important question emerges out is, whether all the particles that upwell in the south Java coast follow the same pathway, or do they simply spread over the surface ocean and are carried westward? In order to illustrate a complete trajectory of all the ITF watermass that upwell in the Java coast, we further examined the pathways of Tracer-3. Note that Tracer-3 was originally initialized at a depth below $160 \mathrm{~m}$ in the ITF initialization box which is in the Indonesian sea region (see Section 2). Therefore, the presence of Tracer- 3 in the south Java surface region is caused by the upwelling. It is shown that Tracer-3 upwelled in the Java coast and followed a southwestward pathway as predicted by the particle trajectory (Figure 2(a) contours). Thus, the tracer pathways are similar to the single particle trajectory described above.

The inset of Figure 2(b) shows the time series of Tracer3 sampled along the south Java coast for the periods of upwelling. Here, we show 18 consecutive months from May of the first year of integration to the December of the second year. For the inset figure, the tracer concentrations range from 0 to 0.4 . A westward migration of the upwelling core along south Java coast is visible from the Tracer-3. The upwelling began near the east coast of south Java by June and it migrated westward with a speed of $0.2 \mathrm{~ms}^{-1}$. By the month of September the core was intensified and located in the west of south Java. This seasonal migration is associated with the migration of along shore wind stress-core. The migration and its speed are consistent with the findings of Susanto et al. [14]. 


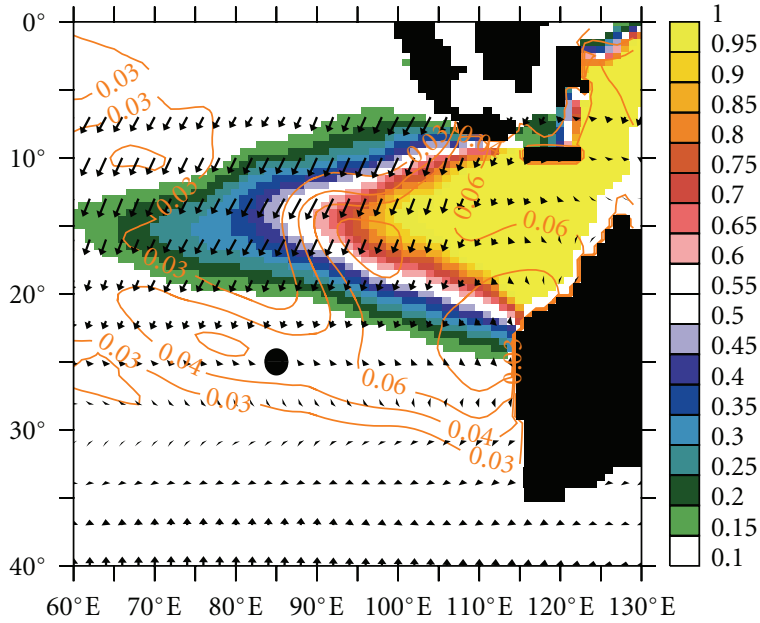

(a)

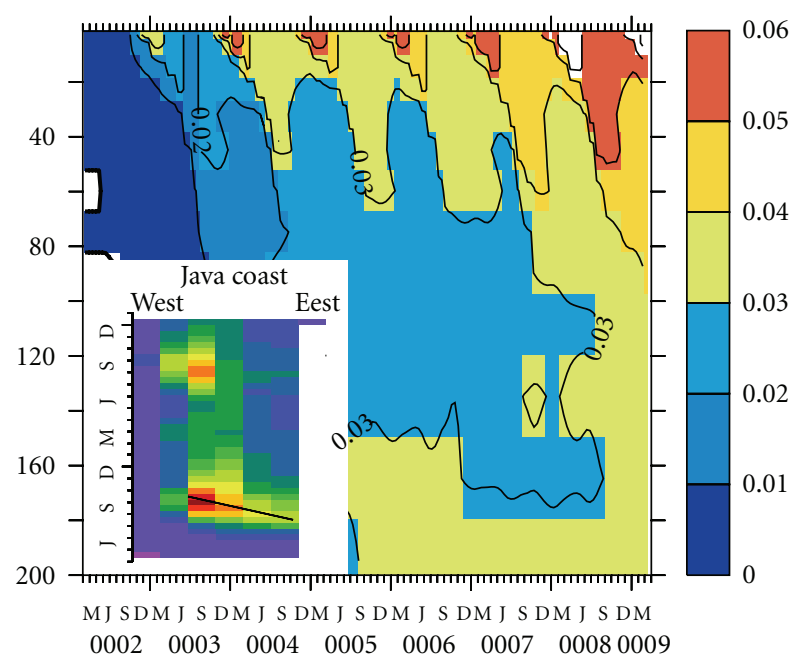

(b)

FIGURE 2: (a) Upwelling of Tracer-3 (initially given from $164.8 \mathrm{~m}$ to $224.1 \mathrm{~m}$ ) and its concentration in surface are shown after four years of integration. The contour (shade) shows the surface (thermocline) concentration. Mean Ekman transport from August to October is shown as vectors. (b) The vertical section of Tracer-3 in time at a point $85^{\circ} \mathrm{E}, 25^{\circ} \mathrm{S}$ (marked as closed circle in (a)). The inset of (b) shows the time series of Tracer- 3 along Java coast. The upwelling center migrates westward at a speed of $0.2 \mathrm{~m} / \mathrm{s}$.

Figure 2(b) shows the vertical evolution of Tracer-3 at a location of $85^{\circ} \mathrm{E}, 25^{\circ} \mathrm{S}$ (shown as closed circle in Figure 2(a)), a point representing just the south of the ZWSC region. This particular point is arbitrarily chosen, because its location is near the southern extend of the ZWSC as well as far from the initialization box so that concentrations will appear as downwelling from top-to-bottom due to the subduction while avoiding the interference of concentrations at $200 \mathrm{~m}$ which is directly advected along the thermocline depths. The vertical section shows that the Tracer- 3 appears at this location first at the surface. This shows the presence of Tracer-3 in the upwelling waters of Java coast and its subsequent Ekman transport through the surface and arrival at the subduction zone. Here, we note that the values in Figure 2(b) range between 0 and 0.06 which is within the white areas of Figure 2(a), whose lowest scale represents between 0.1 and 0.15 . Note that the Figure 2(a) is shown for the thermocline region where the Tracer- 3 was initialized and that explains its higher concentration at that depth. Within the subduction zone, the Tracer-3 gradually sinks downward (Figure 2(b)). This is consistent with the particle trajectory results. It is also worth mentioning that the surface tracer concentrations in Figure 2(b) increases from year 1 through 8 , because of the arrival of more upwelled tracer to that location following each season.

A strong Ekman transport is visible from the south Java coast to the location of subduction zone (shown as arrows in Figure 2(a)). Within the subduction zone the Ekman transport converges (Figure 2(a)). It is interesting to note that the plan view of the surface spreading of the tracer shows a wave-front like shape (see Figure 2(a) contours). This is explained by the seasonal appearance of tracer at the surface due to the upwelling and its subsequent southwestward advection. Thus, the seasonal upwelling caused the tracer to appear in the surface as "pulses", and later it is dispersed by horizontal transport and diffused by vertical mixing.

\section{Tracer Experiments Using Reanalysis Ocean Data}

In this section, we present a series of tracer experiments in an offline model which are driven by an ocean reanalysis data set in order to evaluate the pathway resolved in our OGCM. The SODA.2.0.2 prepared by Carton and Giese [32] is used for this purpose. Since we are only interested in the seasonal upwelling pathways of the ITF in the Java coast, we used an example Year-2000 from the SODA data. Any interannual variability of pathways is not a subject of interest in this study. The choice of this year is that the reanalysis data products incorporate recent and large quantities of observations in the assimilation system on a global scale. Here, the year 2000 is assumed as a scenario closer to the climatology because, in the Pacific, La Niña conditions were prominent during this year. In this case, we calculated the anomalies of year 2000 circulations in the ITF exit region. Figure 3 shows the January and July surface circulations of ITF exit region as resolved in the SODA data for the year 2000. The corresponding anomalies are constructed by subtracting the climatological mean derived from 53 years of the data. Figure 3 shows that the southeastern tropical Indian Ocean surface circulation in the SODA data resembles the observational circulation compiled by Wuffels et al. [26]. For instance, the westward flow along $10^{\circ} \mathrm{S}$ from $100^{\circ} \mathrm{E}$ is the largest component of transport in this region and that is well represented in the SODA circulation. The inflow of ITF in the SODA circulations through Makassar, Lambok, Timor, and Ombai straits are at the same locations as illustrated in [26] (see Figure 3). The color shades represent 


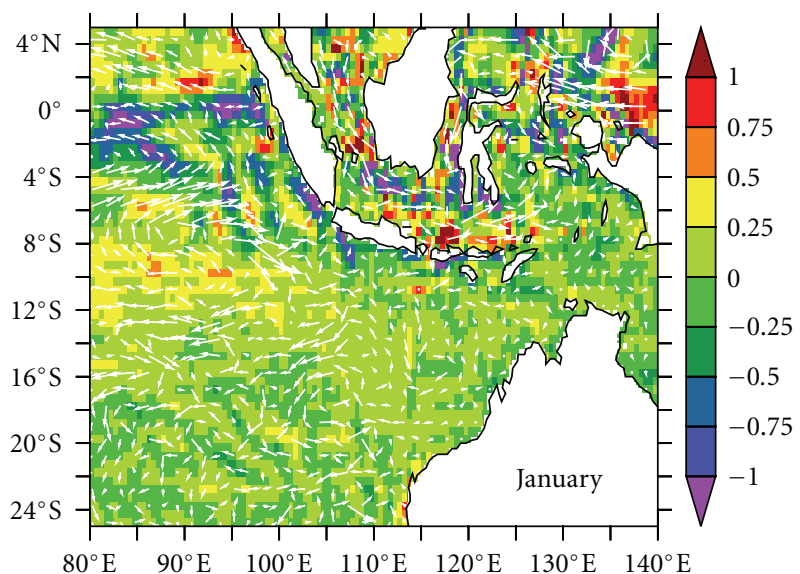

(a)

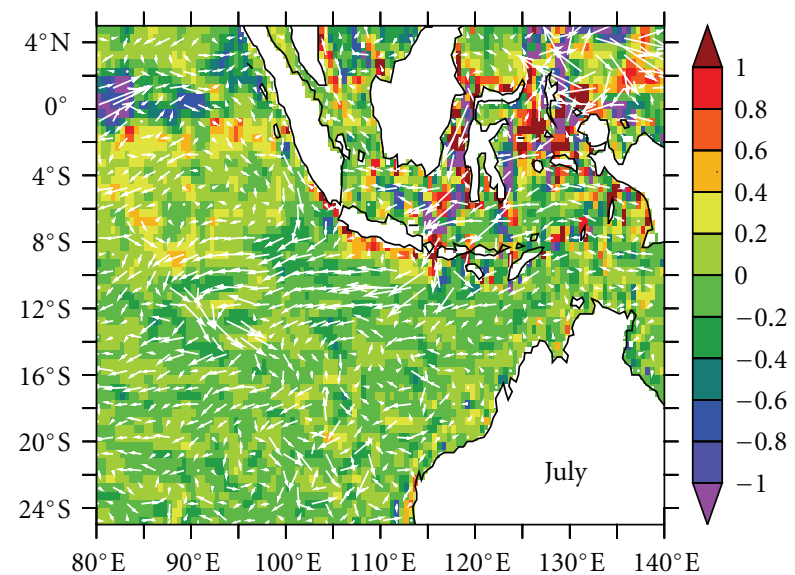

(c)

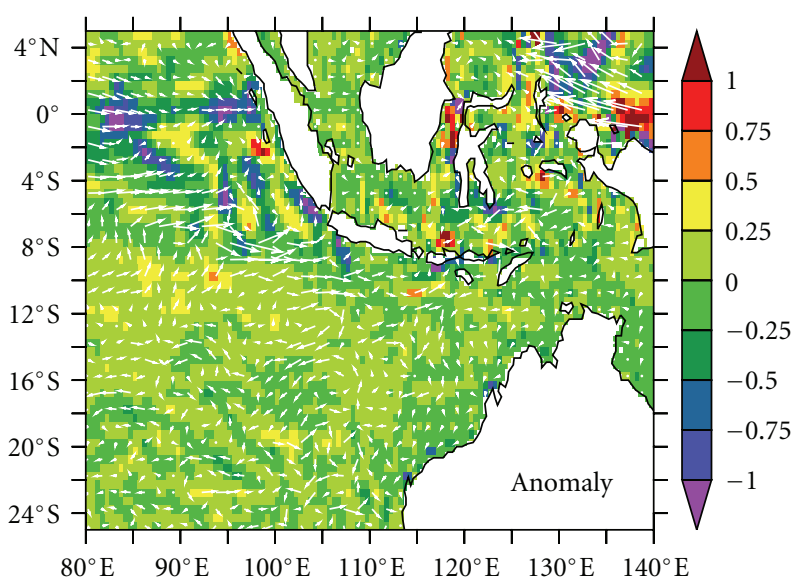

(b)

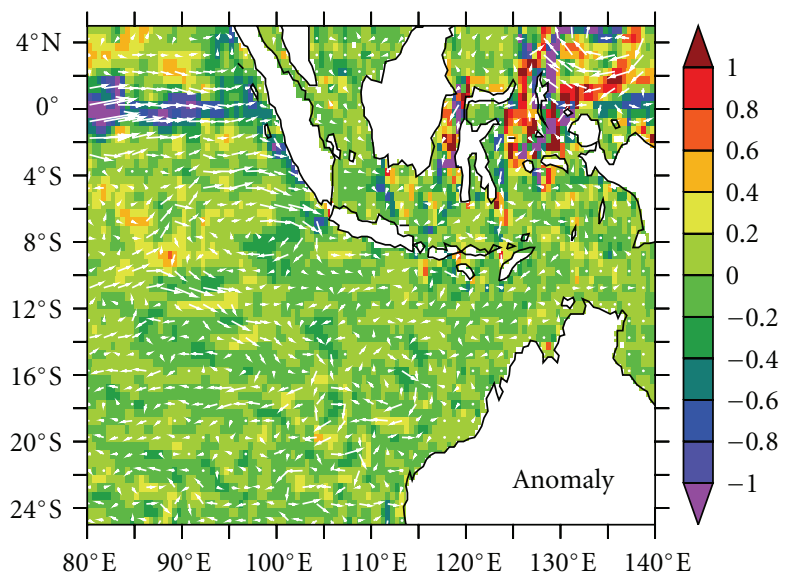

(d)

Figure 3: Circulation (vector) and vertical velocity (shade) at the bottom of first surface grid of SODA data for the year 2000 are shown for January and July. The anomalies of year 2000 calculated based on a climatology of 53 years are shown in (b, d). Units are in ms ${ }^{-1}$.

the vertical velocity at the bottom of first surface grid of the data. During the month of January, the south Java coast experiences a weak downwelling in the year 2000 of the SODA data. During July, the upwelling is visible as large positive values of vertical velocity along the Java coast. The anomaly of this upwelling is rather weak during the year 2000 as seen from the right panel of Figure 3. We calculated the average upwelling over a box along the Java coast with one degree off-shore extension and found that the year 2000 upwelling was weaker than the climatology by a magnitude of $8 \%$. Therefore, the concentration of tracer upwelled in the tracer experiments using SODA data should be viewed with this percentage of uncertainty in its strength. However, we consider using the year 2000 as a representative year because the assimilation in SODA data are moderately benefited from the observations compared to the long-term climatology.

The Year-2000 data is repeated at every year of the simulation in the offline tracer experiments. The tracer solutions are run only for five years in each experiment.

In the experiments using SODA data set, the tracer was released at a depth of $149 \mathrm{~m}-229 \mathrm{~m}$ in the Indonesian sea region over a box of horizontal dimension $116^{\circ} \mathrm{E}-130^{\circ} \mathrm{E}$, $14^{\circ} \mathrm{S}-2^{\circ} \mathrm{S}$. Only one tracer was injected in the above box. The tracer value was kept as 1 in the initialization box throughout the integration. The model advection-diffusion formulation does not allow the tracer concentration to be above 1 in any part of the model domain except for minor numerical overshoots. It was noted that because of the rough topography of the Indonesian Island region and interaction with the local winds, the subsurface tracer may upwell at other coasts of Borneo Islands and several other Indonesian Island chains. In order to make sure that the tracer is not advecting into the southern Java region after being upwelled in any other coast, we suppressed the presence of any advection or diffusion fluxes above $100 \mathrm{~m}$ from the eastern edge of Java coast to the entire tracer initializing domain. This guarantees two conditions: (1) the tracer advects from the initialization region only along a depth range of $100 \mathrm{~m}$ or below to the south Java region, (2) it does not allow any tracer advection to the south Java region after being upwelled from any other coast.

Figures 4(a) and 4(b) show the surface tracer concentration resolved by SODA data at the end of two year simulation. It can be seen that the tracer was upwelled along 


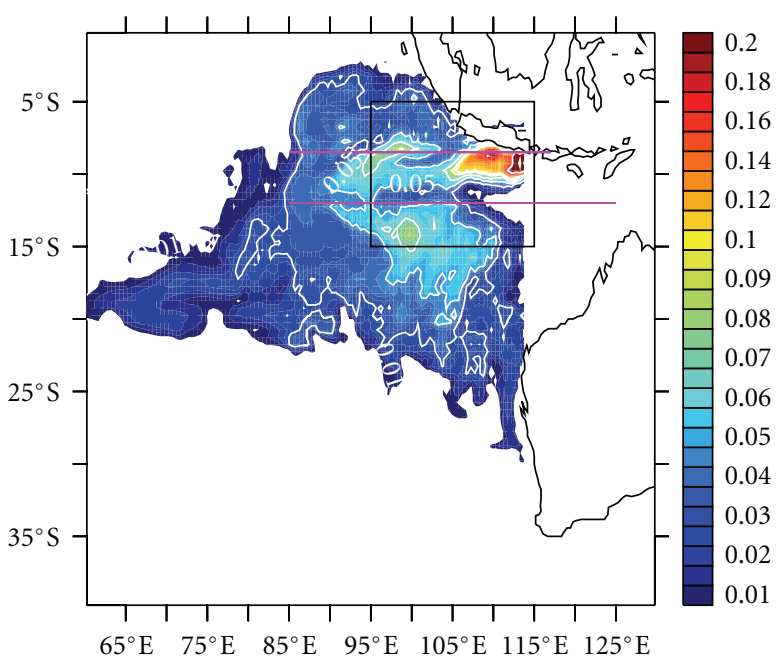

(a)

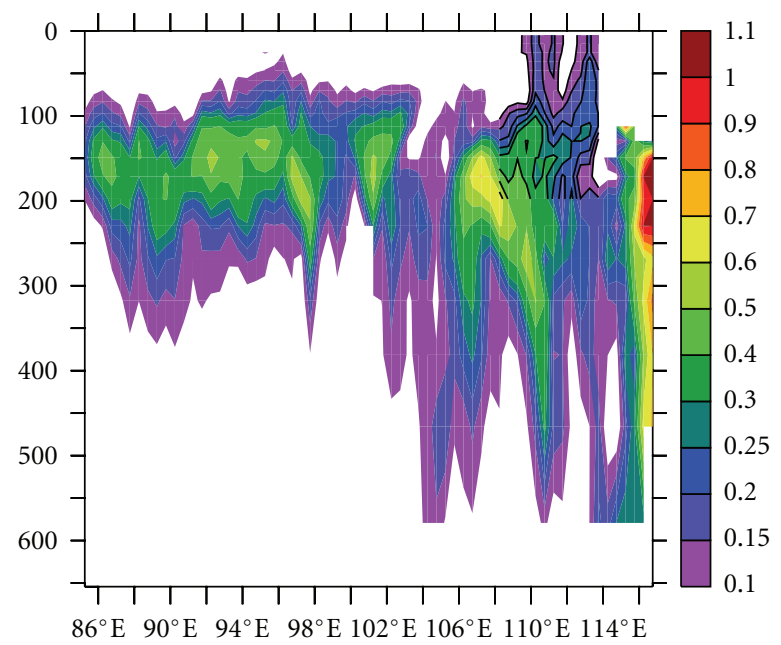

(c)

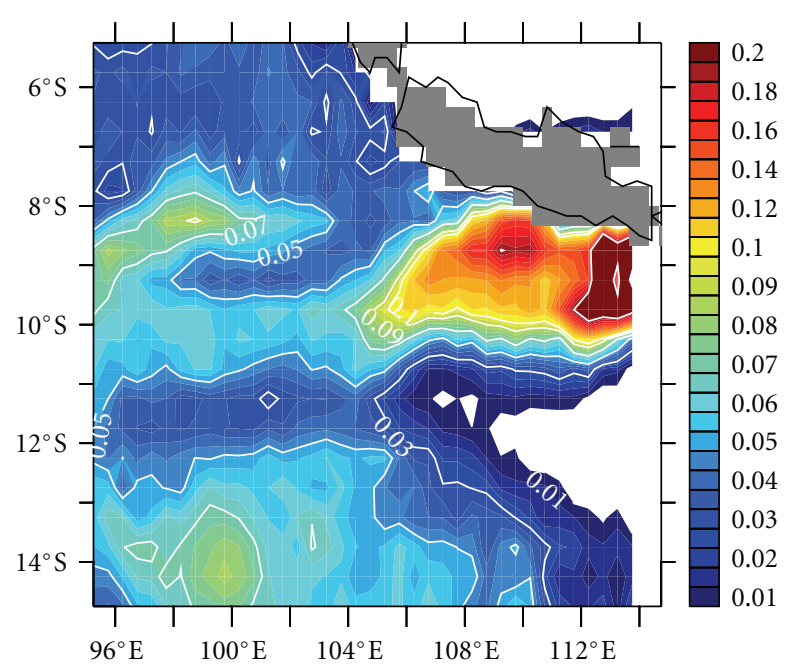

(b)

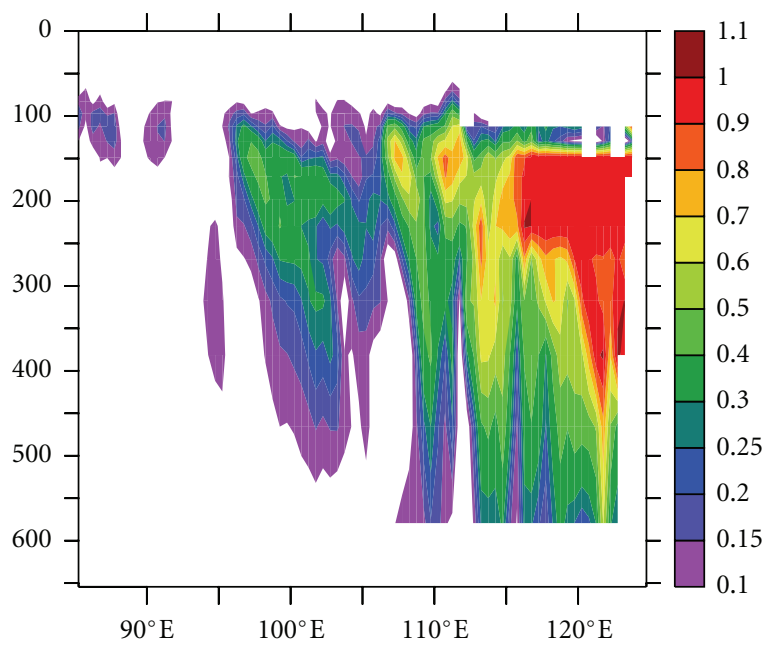

(d)

FIgURE 4: (a) Surface tracer concentration using SODA data set at the end of two year simulation. (b) The zoom of the box shown in (a). (c) The vertical section of tracer using SODA data set along $9^{\circ} \mathrm{S}$. (d) Same as (c) but for $12^{\circ} \mathrm{S}$. Units are in concentration $/ \mathrm{m}^{3}$.

the south Java coast and advected southwestward consistent with our OGCM results. The maximum concentration along the South Java coast shows a clear pattern of upwelling. It is noted that this tracer is appearing at the surface only by the coastal upwelling and is not contaminated by the horizontal advection from any depth above $100 \mathrm{~m}$ (see the paragraph above). The SJC from surface to $120 \mathrm{~m}$ depth is mostly eastward throughout the year and a westward SJUC is observed below this depth [8]. Therefore, the tracer upwelled at the Java coast are those advected below $100 \mathrm{~m}$ depth through SJUC. Figures 4(c) and 4(d) shows vertical sections of tracer along two lines passing through $9^{\circ} \mathrm{S}$ and $12^{\circ} \mathrm{S}$ as shown in Figure 4(a). Moreover, it is shown that the tracer is advected along a depth range of $100 \mathrm{~m}-200 \mathrm{~m}$ representing a true subsurface ITF (Figure 4(c)). At the Java coast, (overlaid as contours in Figure 4(c)), the tracers are entrained vertically to the surface by the coastal upwelling. On the other hand, along $12^{\circ} \mathrm{S}$, the tracer is advecting below $100 \mathrm{~m}$ towards west without any surfacing.
From the SODA solutions, it can be seen that the subsurface ITF upwells at the south Java coast and advects southwestward by Ekman transport. However, the tracer can appear to the surface not only by entrainment at the coast (i.e., here it is upwelling) but also by seasonal vertical mixing. In order to separate the effect of vertical mixing and entrainment on the appearance of subsurface tracer at the surface of south Java coast, we repeated the same experiment with same initialization of tracers but by switching off the seasonal surface vertical mixing. Figure $5(a)$ shows the area averaged tracer concentration in a box off-south Java coast $\left(106^{\circ} \mathrm{E}-113^{\circ} \mathrm{E}, 8^{\circ} \mathrm{S}-9^{\circ} \mathrm{S}\right.$, and $\left.0-30 \mathrm{~m}\right)$ for the control tracer run and nonvertical-mixing run. It can be seen that the tracer concentrations in both runs are identical, which reveal the fact that seasonal vertical mixing has negligible role on bringing the tracer to the surface in the south Java coast. The control experiment has slightly less tracer concentration than the nonvertical-mixing experiment especially in the month of October, which shows that the 


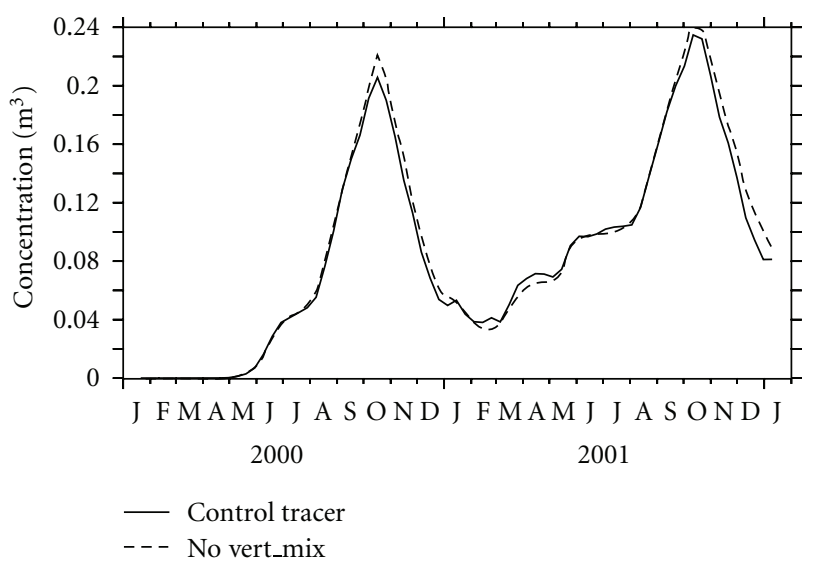

(a)

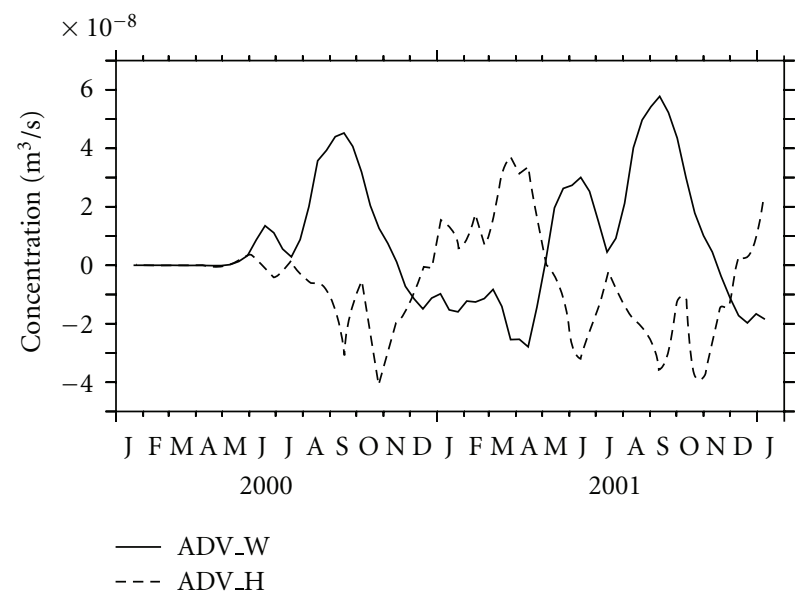

(b)

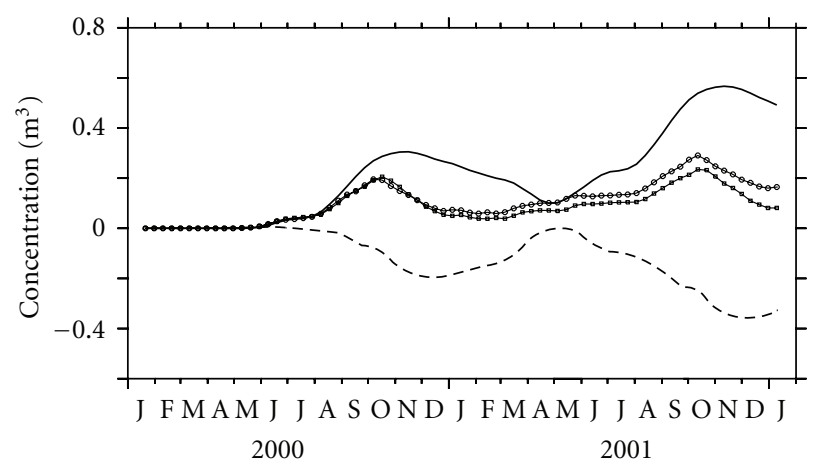

- (a) Tracer concentration by ADV_W

- - - (b) Tracer concentration by ADV_H

.000000000 (a) $+($ b)

.......... Control tracer

(c)

FIGURE 5: (a) Area averaged tracer concentration in region in south Java coast $\left(106^{\circ} \mathrm{E}-113^{\circ} \mathrm{E}, 8^{\circ} \mathrm{S}-9^{\circ} \mathrm{S}, 0-30 \mathrm{~m}\right)$ in the SODA experiment for the control tracer experiment and nonverticalmixing experiment cases. (b) The vertical advection and horizontal advection fluxes in the same box. Positive values shows an increase in concentration. (c) The time interval integral of vertical and horizontal fluxes in the same box and their summation are shown. The control tracer experiment is also shown. vertical mixing fluxes counteract the entrainment due to the upwelling.

It is also shown that upwelling along the south Java coast starts by July and peaks during the October and slowly decays during the other parts of the year (Figure 5(a)). The Figure 5(b) shows the vertical and horizontal advection components of the tracer in the same box from the south Java coast. It can be seen that the vertical entrainment (ADV_W) has strong positive fluxes from July to October indicating an upwelling process. At the same period, the horizontal advection (ADV_H) has an opposite effect which expels the tracer out of the box. This indicates the Ekman transport away from the coast after upwelling. Figure 5(c) shows the contribution from both horizontal advection and entrainment fluxes to the total concentration of tracer. It can be seen that the sum of horizontal advective and entrainment fluxes yields a net tracer concentration which is equivalent to the control tracer experiment. The small difference between (a) + (b) in Figure 5(c) and control tracer is the residual by the vertical mixing and horizontal diffusion processes.

The SODA tracer experiments revealed that the subsurface ITF can upwell in the south Java coast. It is also established that the entrainment by the coastal upwelling alone can bring the subsurface ITF to the surface in the south Java coast. Thus the solutions we found in our OGCM have been verified by the reanalysis ocean data currents. Moreover, the tracer experiments using reanalysis ocean currents enabled us to separate the effect of entrainment, vertical mixing, and horizontal advection on the total upwelling of subsurface ITF at the south Java coast. This is a real advantage of using offline ocean data products to resolve particular pathways of water masses.

In the following part, we will examine the pathway of the ITF after upwelling at the south Java coast. Our OGCM results suggested that after upwelling, the ITF advects southwestward as trapped in the surface Ekman layer and subducts the ZWSC region. In order to identify this feature, we tracked the upwelling water from the South Java region using the SODA reanalysis data. In the new set of experiments, we initialized the tracer right at the south Java coast. The tracer initialization was made proportional to the observed upwelling in the south Java coast $\left(106^{\circ} \mathrm{E}-113^{\circ} \mathrm{E}\right.$, $8^{\circ} \mathrm{S}-9^{\circ} \mathrm{S}$, and $10 \mathrm{~m}$ ). In order to represent the upwelling along the coast, the tracer was injected whenever the advection velocities at the bottom of the model grid were found as positive (i.e., upward). Since we are interested in the surface advection and then subduction pathways of the tracer, the seasonal surface vertical mixing was switched off in this run as well. The tracer was run for five years by repeating the SODA data of Year-2000.

Figures 6(a)-6(d) show evolution of upwelled tracer from the south Java coast for the first two years of the run. From July to September, the surface tracer concentration shows the origin from the south Java coast and subsequent advection southwestward. Figure 6(b) shows the evolution of this plume from October to November and Figure 6(c) shows the evolution from December to the February of the following year. The progression of plume from Figures 6(a)6(d) shows two typical features: (1) the plume is upwelled 


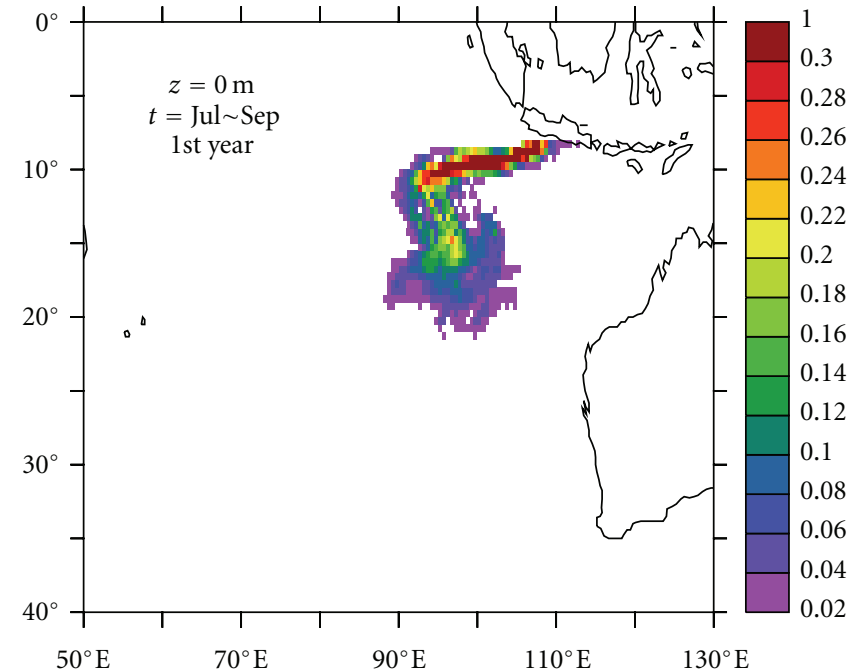

(a)

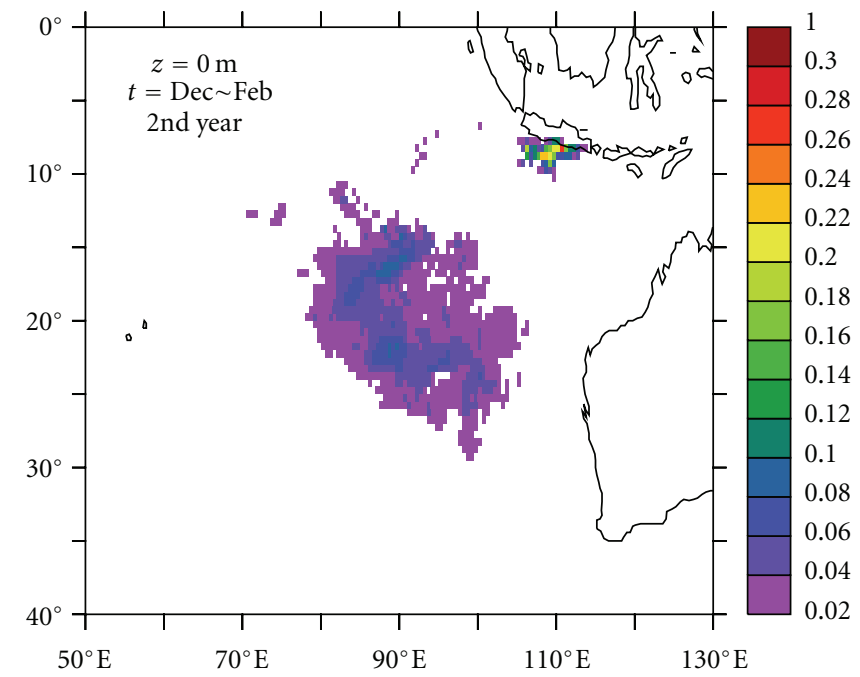

(c)

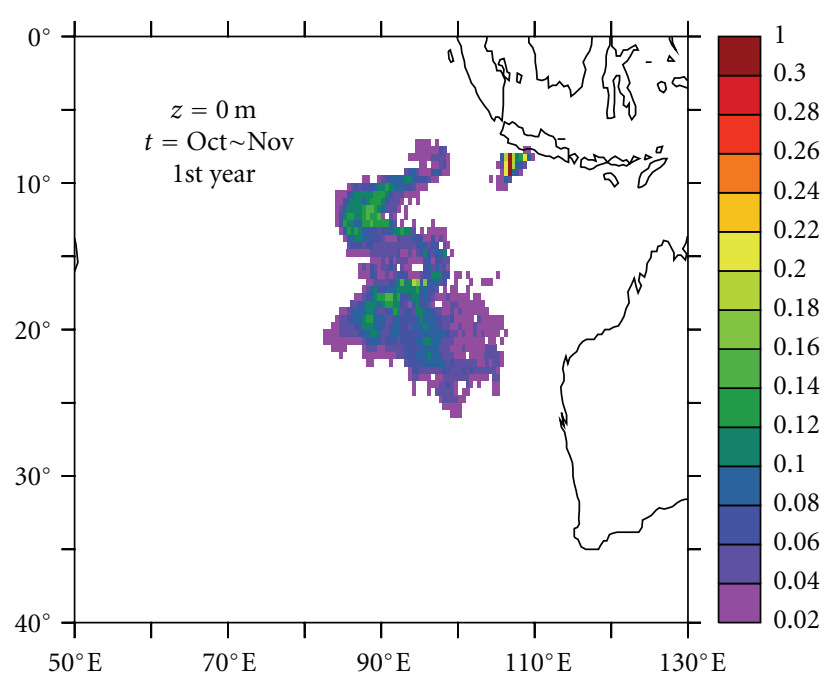

(b)

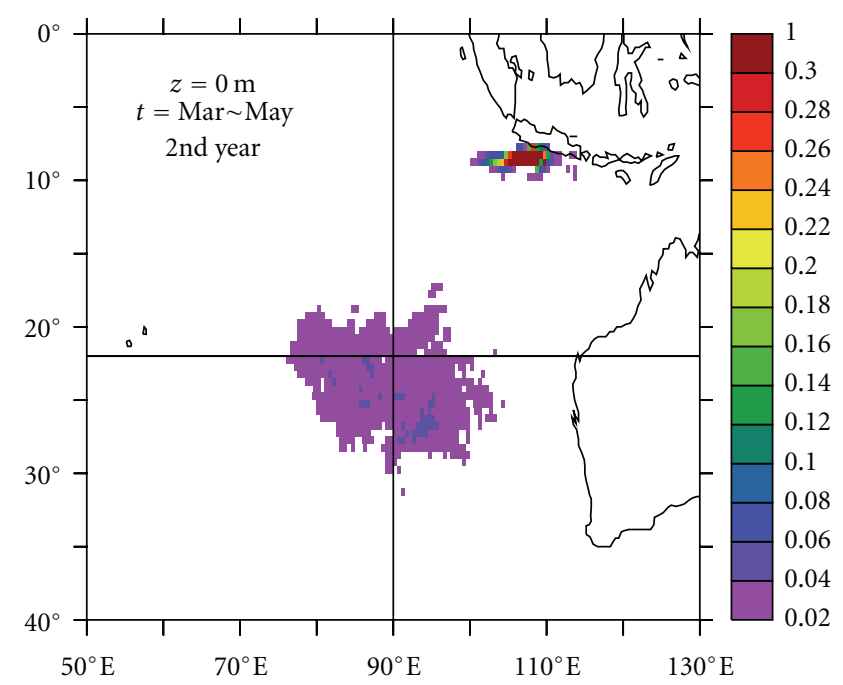

(d)

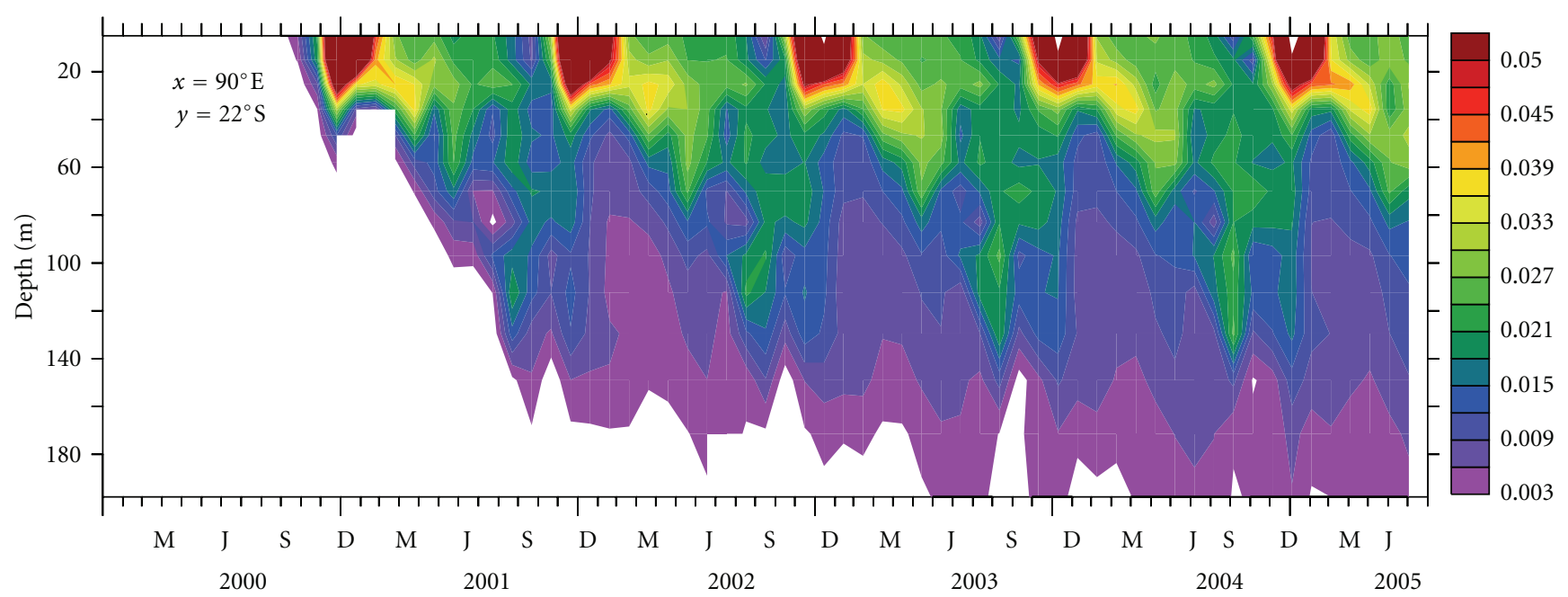

(e)

Figure 6: Continued. 


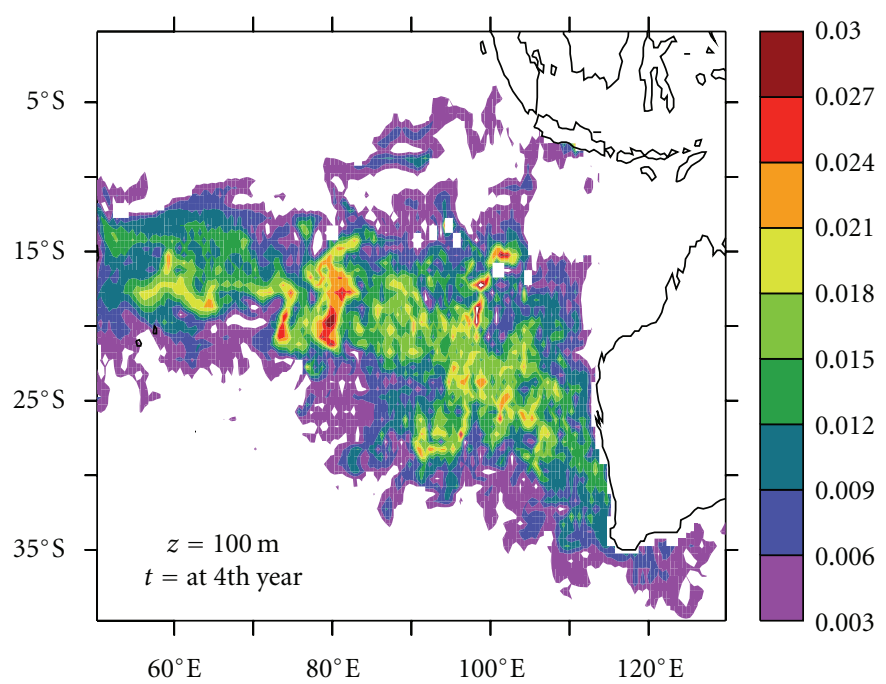

(f)

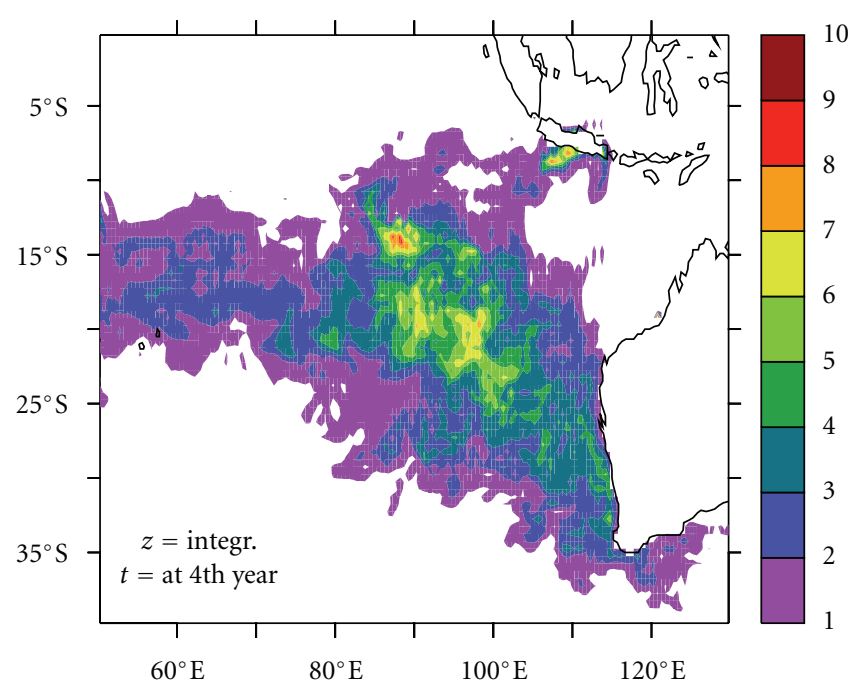

(g)

FIgURE 6: ((a), (b), (c), and (d)) The SODA surface tracer concentration with initialization in the south Java coast during upwelling in a box of $106^{\circ} \mathrm{E}-113^{\circ} \mathrm{E}, 8^{\circ} \mathrm{S}-9^{\circ} \mathrm{S}, 0 \mathrm{~m}$ for three different set of averaging period as labeled. (e) The vertical evolution of tracer at a point of $90^{\circ} \mathrm{E}$, $22^{\circ}$ S. (f) Tracer concentration at the end of 4 th year at $100 \mathrm{~m}$ depth. (g) Same as (f) but for vertical integral. Units are in concentration/m ${ }^{3}$.

and advected southwestward in the surface, and (2) the plume is diluted without much spreading in the horizontal direction which shows a possible downward transport by subduction. In order to illustrate the downward transport, we show the vertical evolution of tracer at a location $90^{\circ} \mathrm{E}$, $22^{\circ} \mathrm{S}$ in Figure 6(e) for five years of the simulation. It can be seen that the tracer appears in the surface at first during the month of December, which is a time required by the Ekman transport to carry the tracer from the upwelling zone (south Java) to the $90^{\circ} \mathrm{E}, 22^{\circ} \mathrm{S}$. This is consistent with the particle trajectory and tracer experiments using our OGCM solutions (Figures 1(a) and 1(b)). Upon arriving at the subduction zone, the tracer starts sinking gradually in time. Figure 6(e) shows a gradual vertical motion of tracer that is consistent with what we have resolved in our OGCM (Figure 2(b)). The reason for this subduction is the presence of ZWSC existing over this region (see Figure 1(a)).

Figure 6(f) shows the tracer concentration at $100 \mathrm{~m}$ depth at the end of 4 th year of the simulation. The subducted ITF was carried northwestward in the subsurface. This is consistent with the Lagrangian particle trajectory results of Valsala and Ikeda [10]. Figure 6(g) shows the vertically integrated (full-depth) tracer concentration at the end of 4th year of the simulation. This shows the returning pathway of the water that upwelled at the south Java coast to the thermocline and then its journey to the western Indian Ocean. This coincides with the pathways resolved from all the ITF that is subducted at the northwestern coast of Australia in the work of Valsala and Ikeda [10].

\section{Volume Transport in the Upwelling Pathways}

The shelf circulation along the south Java coast (South Java Current; SJC) has a strong semiannual signal with eastward flow during May and November. Sprintall et al. [18] attributed this to the coastal Kelvin wave which is forced by remote equatorial winds in the Indian Ocean. The coastal winds are south-easterlies during the boreal summer and expected to induce a downstream (northwestward) coastal flow. Our OGCM derived SJC is compared with the one year observation of Sprintall et al. [18] in Figure 7(a) and shows reasonable agreement in the directions. The OGCM results are shown at $109.5^{\circ} \mathrm{E}, 8.5^{\circ} \mathrm{S}$. The mooring location of Sprintall et al. [18] was $109.5^{\circ} \mathrm{E}, 8.5^{\circ} \mathrm{S}$. It is noted that the mooring observation in [18] was carried out during 19971998, when the Indian Ocean experienced a strong Dipole Mode event [20], and hence, the observations were not exactly a representation of climatological SJC. During June and July, the observations suggest a westward flow. In the model this westward flow is resolved from July to September as an intensified shallow $(0-30 \mathrm{~m})$ current.

A vertical section of SJC near the observational point is shown in Figure $7(\mathrm{c})$. This section is shown at $109.5^{\circ} \mathrm{E}$ and along $8^{\circ} \mathrm{S}-10^{\circ} \mathrm{S}$. During August, the SJC is eastward, while the ITF flows westward $100 \mathrm{~km}$ off the coast. The corresponding vertical velocity shows that the upwelling center concentrates on 1 degree down the coast, but not exactly at the coast as expected for coastal upwelling (Figure 7(c) contours). Thus, in addition to the coastal upwelling, which is partially obscured by the coastal Kelvin waves [18], the upwelling $100-\mathrm{km}$ off the coast occurs due to the local wind stress curl and causes the ITF to upwell there. The model vertical velocity shows a zero contour which shoals from $800 \mathrm{~m}$ to $300 \mathrm{~m}$ toward the coast (Figure 7(c)). The positive vertical velocity causes the deep tracer to appear at the surface.

The combined analysis of particle trajectories and tracer pathways reveals that the upwelling component of ITF at 


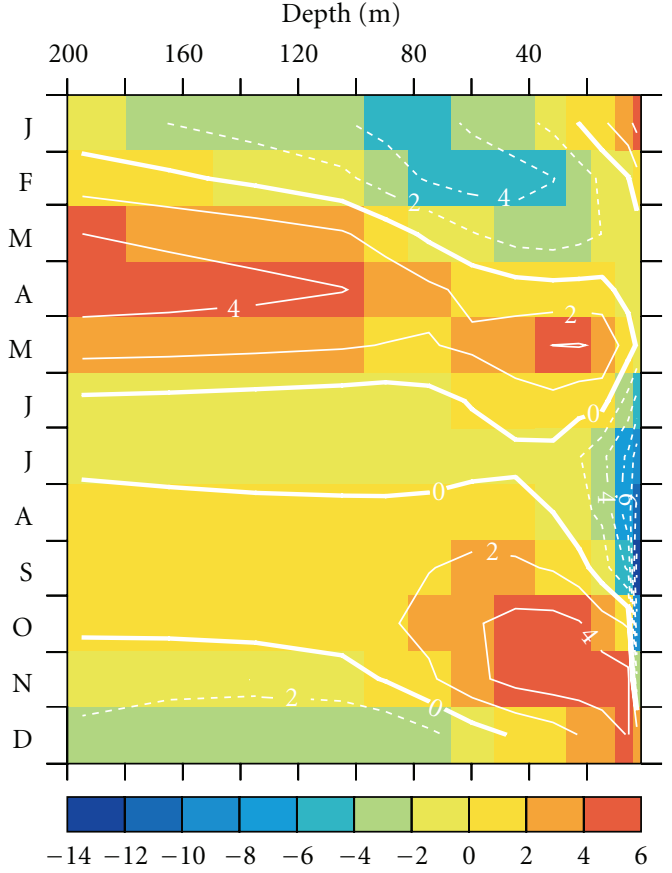

(a)

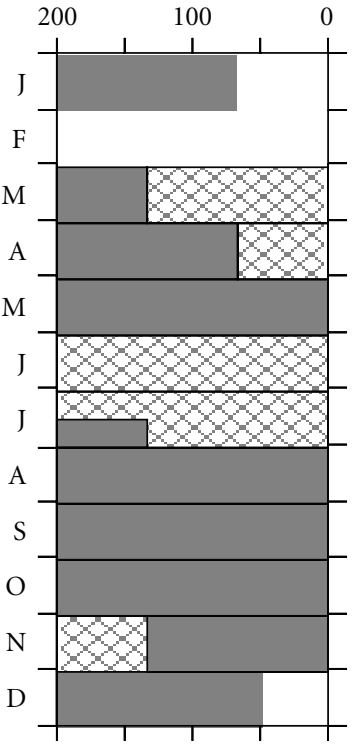

(b)

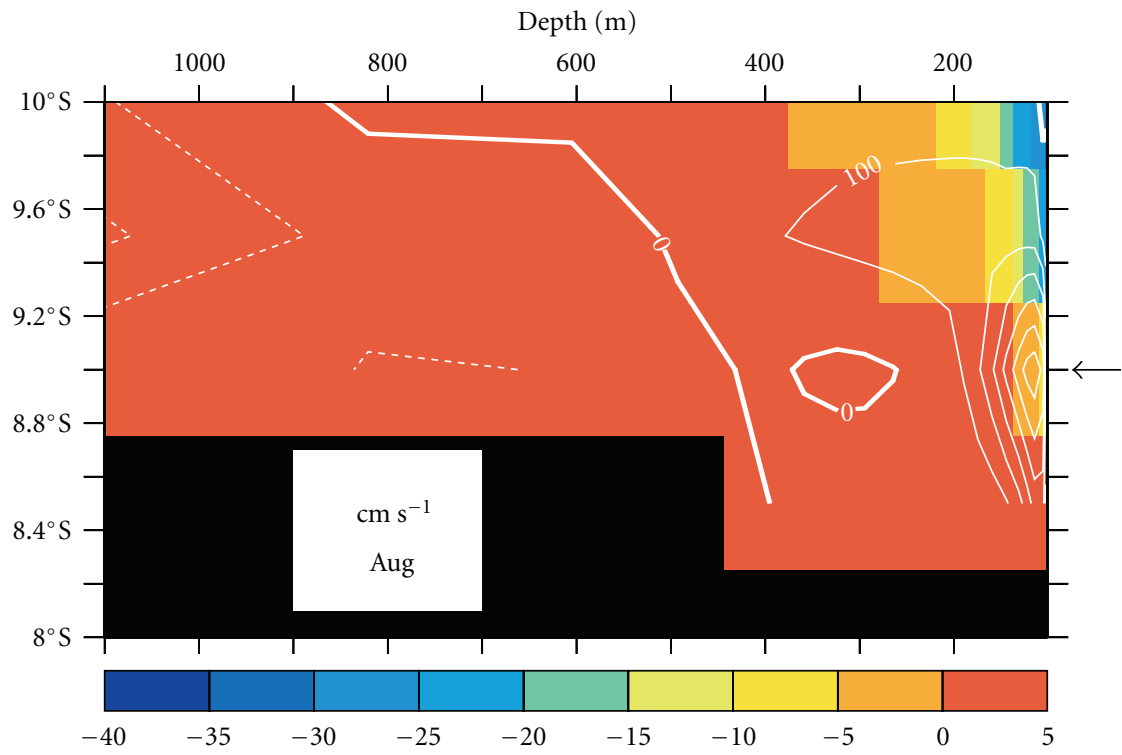

(c)

FIGURE 7: (a) OGCM zonal current at a location close to the south Java coast and (b) corresponding observations from Sprintall et al. [18]. The shade shows the eastward current and the pattern shows the westward current. (c) The horizontal shelf velocity (shade) and vertical velocity (contour) resolved in OGCM. Positive shade, contour means an eastward, upward velocity, respectively.

the south Java coast is largely supplied from the Lombok Throughflow. However, the model does not have Ombai strait separately but coalesced with the model Timor strait. Therefore, the flow through the Ombai strait may provide ITF water that can participate in the south Java upwelling. We calculated the amount of tracer flux that upwelled through a box which covers the Java coast and at the base of 20-m depth and compared with the tracer flux (Tracer-2 and Tracer-3) that coming out of the Lombok Strait from our OGCM results. The upwelling is at the peak during August to October (see Figure 1(a)). This water mass took three months from the Lombok Strait to the upwelling zone, as inferred from the particle trajectory (see Figure 1(a)). Thus, a three month lag was applied in 
the comparison of both tracer fluxes. It was found that $45 \%$ of the below $100 \mathrm{~m}$ Lombok Throughflow upwelled at Java coast during August. This corresponds to an inflow at the Lombok Channel during three months which is nearly $1 \mathrm{~Sv}$ in the model (below $100 \mathrm{~m}$ ). Thus, $0.4 \mathrm{~Sv}$ of the Lombok Throughflow was uplifted to the surface at Java coast during August. The flux rapidly fell in the other months when the upwelling center migrates northwestward along the Java coast. However, the tracer experiments with SODA data show that our OGCM overestimates the amount of upwelling of ITF in the south Java coast. The SODA tracer result shows a maximum concentration of 0.22 by the month of October in the surface level. Considering the initial concentration of 1.0 in the SODA tracer experiments, the maximum tracer concentration in the south Java coast represents only less than $25 \%$ of the subsurface ITF expelled through the Lombok strait.

\section{Discussion and Conclusion}

The ITF enters into the Indian Ocean after passing through a numerous chains of Islands with rough topographies. The complex topographies and the subsequent effects of tides and the local wind stress cause a relatively shallow ITF waters to mix vigorously in the exit region [27]. Thus, a numerous pathways of ITF within the Indonesian Island chains and exit region may exist. In this study, we propose that the ITF can upwell from a relatively deeper position of $100 \mathrm{~m}$ or below to the surface at the south Java coast. Du et al. [17] have noticed that the warm advection of ITF is one of the reasons for relatively warm SST in the upwelling region of south Java. Our study shows that the upwelling is also a reason to bring the ITF to the surface in the south Java region.

The Lagrangian trajectories and passive tracers can be used to track the water masses more efficiently, especially, at situations where classical T-S analysis fails to represent a water mass for a long term when complex mixing and re-distribution of water masses are involved. Our study made use of these two tools in order to look at a typical pathway of subsurface ITF in the exit region. Moreover, the same technique is extended over a reanalysis data and used effectively to verify the pathways resolved in the OGCM.

The surface pathway of subsurface ITF resolved in this study is relatively "short", because it subducts right at the center of the ZWSC (nearly $20^{\circ} \mathrm{S}$ ). After upwelling at the coast of Java, the ITF is advected by Ekman transport and reaches this subduction zone in less than 260 days. The evidence of upwelling and southwestward advection due to Ekman transport has been confirmed with reanalysis ocean currents. An important open question is "How much does this upwelling affect the local SST variability of off-south Java coast?" and is a subject to study with a high-resolution model.

6.1. Uncertainty. Although the pathways derived from OGCM and SODA reanalysis data are generally consistent to each other, we discuss a few points of uncertainty that may present in the results. One major source of uncertainty is that the resolution of our OGCM is rather coarse to resolve the coastal upwelling realistically. A $0.5^{\circ}$ meridional resolution may not yield the accurate strength of upwelling. The Java coast is about $8^{\circ}$ away from the equator. The baroclinic Rossby radius of deformations are larger near the equator and the $0.5^{\circ}$ may resolve fundamental features of the upwelling. However, the strength of the upwelling and coastal currents may not be resolved completely in the present configuration of our OGCM. However, the SODA reanalysis data (which was originally produced on a much finer resolution; see Section 2) gave consistent results with our OGCM derived pathways. Therefore, the pathways derived from our OGCM are valid compared with the reanalysis data examined here.

Another source of uncertainty is the repeated usage of year 2000 circulation from the reanalysis data in order to examine the upwelling pathways of the ITF. This may carry an element of interannual variability of this particular year in the resulted pathways. We examined the anomaly of upwelling along the Java coast during the year 2000 compared to the long-term climatology. It can be found that $8 \%$ of reduced upwelling was a general feature of year 2000. This may add uncertainties in the strength (or concentration) of tracers upwelled in the Java coast in the SODA tracer experiment. The anomalies of circulation in the route of the suggested pathway are, however, minor in the year 2000 circulation (see Figure 3 ).

The tide-induced mixing is not accounted neither in our OGCM nor in the reanalysis data. Therefore, the information on the impact of tidal processes on the pathway is missing. A more higher resolution regional model including the complex topography of Indonesian Islands and tidal processes is required for the detailed investigation of numerous pathways of ITF within the exit region. Also, additional effort should be made to force such regional high resolution models with atmospheric forcing whose land-ocean transitions are realistically calculated. Such complex processes, however, likely to have less influence on the seasonal pathways examined here which is fundamentally related to the seasonal surface forcing.

The offline model used here has proven capacity to resolve inventories of tracers in the ocean realistically (Valsala et al. [33]). The offline model parameterizes the vertical mixing and other subgrid scale processes which were actually parts of the model physics of the parent model from where the offline currents and other variables are derived. Therefore, recalculating such processes internally in the offline model can be rightly justified.

\section{Acknowledgments}

The first author was supported from COE, Graduate School of Environmental Science, Hokkaido University, Sapporo, Japan, and Mitsubishi Trust Yamamuro Memorial Scholarship Foundation, Tokyo, during the first half of this work and now supported as a postdoctoral fellow in CGER, NIES. The model and technical notes were provided by the CSIRO, Marine Research, Australia. Ferret software (NOAA/PMEL) is used for plotting. 


\section{References}

[1] A. C. Hirst and J. S. Godfrey, "The role of Indonesian throughflow in a global ocean GCM," Journal of Physical Oceanography, vol. 23, no. 6, pp. 1057-1086, 1993.

[2] A. L. Gordon and R. A. Fine, "Pathways of water between the Pacific and Indian oceans in the Indonesian seas," Nature, vol. 379, no. 6561, pp. 146-149, 1996.

[3] N. Schneider, "The Indonesian Throughflow and the global cliamte system," Journal of Climate, vol. 11, no. 4, pp. 676-689, 1998.

[4] R. C. Wajsowicz and E. K. Schneider, "The Indonesian throughflow's effect on global climate determined from the COLA Coupled Climate System," Journal of Climate, vol. 14, no. 13, pp. 3029-3042, 2001.

[5] R. C. Wajsowicz, "Air-sea interaction over the Indian Ocean due to variations in the Indonesian throughflow," Climate Dynamics, vol. 18, no. 5, pp. 437-453, 2002.

[6] A. L. Gordon, R. D. Susanto, A. Ffield, B. A. Huber, W. Pranowo, and S. Wirasantosa, "Makassar strait throughflow, 2004 to 2006," Geophysical Research Letters, vol. 35, no. 24, Article ID L24605, 2008.

[7] A. L. Gordon, J. Sprintall, H. M. Van Aken et al., "The Indonesian throughflow during 2004-2006 as observed by the INSTANT program," Dynamics of Atmospheres and Oceans, vol. 50, no. 2, pp. 115-128, 2010.

[8] J. Sprintall, S. Wijffels, R. Molcard, and I. Jaya, "Direct evidence of the South Java Current system in Ombai Strait," Dynamics of Atmospheres and Oceans, vol. 50, no. 2, pp. 140 156, 2010.

[9] H. M. van Aken, I. S. Brodjonegoro, and I. Jaya, "The deepwater motion through the Lifamatola Passage and its contribution to the Indonesian throughflow," Deep-Sea Research, vol. 56, no. 8, pp. 1203-1216, 2009.

[10] V. K. Valsala and M. Ikeda, "Pathways and effects of the Indonesian Throughflow water in the Indian Ocean using particle trajectory and tracers in an OGCM," Journal of Climate, vol. 20, no. 13, pp. 2994-3017, 2007.

[11] M. A. Haines, R. A. Fine, M. E. Luther, and Z. Ji, "Particle trajectories in an Indian Ocean model and sensitivity to seasonal forcing," Journal of Physical Oceanography, vol. 29, no. 4, pp. 584-598, 1999.

[12] Q. Song, A. L. Gordon, and M. Visbeck, "Spreading of the Indonesian throughflow in the Indian Ocean," Journal of Physical Oceanography, vol. 34, no. 4, pp. 772-792, 2004.

[13] C. M. Domingues, M. E. Maltrud, S. E. Wijffels, J. A. Church, and M. Tomczak, "Simulated Lagrangian pathways between the Leeuwin Current System and the upper-ocean circulation of the southeast Indian Ocean," Deep-Sea Research, vol. 54, no. 8-10, pp. 797-817, 2007.

[14] R. D. Susanto, A. L. Gordon, and Q. Zheng, "Upwelling along the coasts of Java and Sumatra and its relation to ENSO," Geophysical Research Letters, vol. 28, no. 8, pp. 1599-1602, 2001.

[15] T. Qu and G. Meyers, "Seasonal variation of barrier layer in the southeastern tropical Indian Ocean," Journal of Geophysical Research, vol. 110, no. 11, Article ID C11003, pp. 1-13, 2005.

[16] M. E. Conkright, R. A. Locamini, H. E. Gracia et al., World Ocean Atlas 2001: Objective Analyses, Data Statistics, and Figures, CD-ROM Documentation, National Oceanographic Data Center, Md, USA, 2001.

[17] Y. Du, T. Qu, G. Meyers, Y. Masumoto, and H. Sasaki, "Seasonal heat budget in the mixed layer of the souteastern tropical Indian Ocean in a high-resolution ocean general circulation model," Journal of Geophysical Research, vol. 110, Article ID C04012, 15 pages, 2005.

[18] J. Sprintall, J. Chong, F. Syamsudin et al., "Dynamics of the South Java current in the Indo-Australian basin," Geophysical Research Letters, vol. 26, no. 16, pp. 2493-2496, 1999.

[19] Y. You and M. Tomczak, "Thermocline circulation and ventilation in the Indian Ocean derived from water mass analysis," Deep-Sea Research, vol. 40, no. 1, pp. 13-56, 1993.

[20] N. H. Saji, B. N. Goswami, P. N. Vinayachandran, and T. Yamagata, "A dipole mode in the tropical Indian ocean," Nature, vol. 401, no. 6751, pp. 360-363, 1999.

[21] R. Murtugudde, B. N. Goswami, and A. J. Busalacchi, "Air-sea interaction in the southern tropical Indian Ocean and its relations to interannual variability of the monsoon over India," in Proceedings of the International Conference on Monsoon and Hydrologic Cycle, pp. 184-188, Korean Meteorological Agency, Korea, 1998.

[22] V. Valsala, S. Maksyutov, and R. Murtugudde, "Possible interannual to interdecadal variabilities of the Indonesian throughflow water pathways in the Indian Ocean," Journal of Geophysical Research, vol. 115, no. 10, 2010.

[23] S. Wijffels and G. Meyers, "An intersection of oceanic waveguides: variability in the Indonesian throughflow region," Journal of Physical Oceanography, vol. 34, no. 5, pp. 1232-1253, 2004.

[24] V. Valsala, "First and second baroclinic mode responses of the tropical Indian Ocean to interannual equatorial wind anomalies," Journal of Oceanography, vol. 64, no. 4, pp. 479494, 2008.

[25] T. Qu and G. Meyers, "Seasonal characteristics of circulation in the southeastern tropical Indian Ocean," Journal of Physical Oceanography, vol. 35, no. 2, pp. 255-267, 2005.

[26] S. E. Wuffels, G. Meyers, and S. J. Godfrey, "A 20-yr average of the Indonesian throughflow: regional currents and the interbasin exchange," Journal of Physical Oceanography, vol. 38, no. 9, pp. 1965-1978, 2008.

[27] A. Schiller, J. S. Godfrey, P. C. McIntosh et al., "A new version of the Australian Community Ocean Model for Seasonal Climate Prediction," Tech. Rep. 238, CSIRO, 2002, pp. 1-79.

[28] D. Chen, L. M. Rothstein, and A. J. Busalacchi, "A hybrid vertical mixing scheme and its application to tropical ocean models," Journal of Physical Oceanography, vol. 24, no. 10, pp. 2156-2179, 1994.

[29] S. A. Josey, E. C. Kent, and P. K. Taylor, "New insights into the ocean heat budget closure problem from analysis of the SOC air-sea flux climatology," Journal of Climate, vol. 12, no. 9, pp. 2856-2880, 1999.

[30] A. da Silva, A. C. Young, and S. Levitus, Atlas of Surface Marine Data, vol. 1 of Algorithms and Procedures, NOAA Atlas NESDIS 6, U.S. Department of Commerce, Washington, DC, USA, 1994.

[31] S. Hellerman and M. J. Rosenstein, "Normal monthly windstress over the world ocean with error estimates," Journal of Physical Oceanography, vol. 13, no. 7, pp. 1093-1104, 1983.

[32] J. A. Carton and B. S. Giese, "A reanalysis of ocean climate using Simple Ocean Data Assimilation (SODA)," Monthly Weather Review, vol. 136, no. 8, pp. 2999-3017, 2008.

[33] V. Valsala, S. Maksyutov, and I. Motoyoshi, "Design and validation of an offline oceanic tracer transport model for a carbon cycle study," Journal of Climate, vol. 21, no. 12, pp. 2752-2769, 2008.

[34] K. Bryan and L. J. Lewis, "A water mass model of the world ocean," Journal of Geophysical Research, vol. 85, no. 5, pp. 2503-2518, 1979. 
[35] S. M. Griffies and R. W. Hallberg, "Biharmonic friction with a Smagorinsky-like viscosity for use in large-scale eddypermitting ocean models," Monthly Weather Review, vol. 128, no. 8, pp. 2935-2946, 2000.

[36] P. R. Gent and J. C. McWilliams, "Isopycnal mixing in Ocean circulation models," Journal of Physical Oceanography, vol. 20, pp. 150-155, 1990.

[37] J. Karstensen and D. Quadfasel, "Water subducted into the Indian Ocean subtropical gyre," Deep-Sea Research, vol. 49, no. 7-8, pp. 1441-1457, 2002.

[38] F. A. Schott, S. P. Xie, and J. P. McCreary, "Indian ocean circulation and climate variability," Reviews of Geophysics, vol. 47, no. 1, Article ID RG1002, pp. 1-46, 2009. 

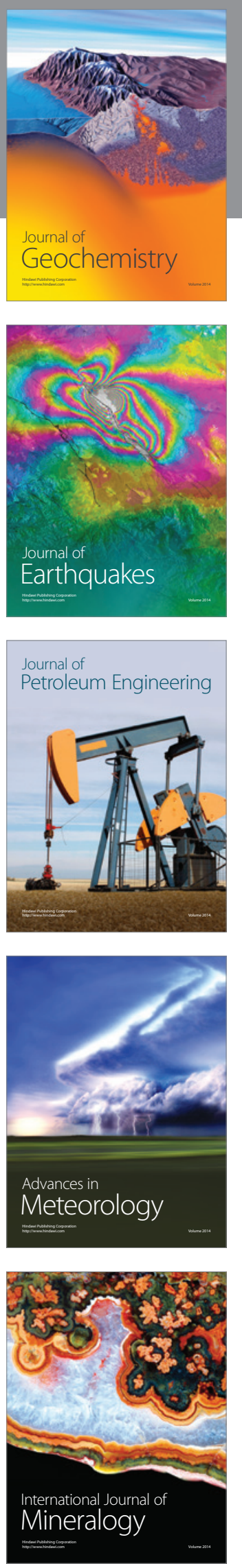
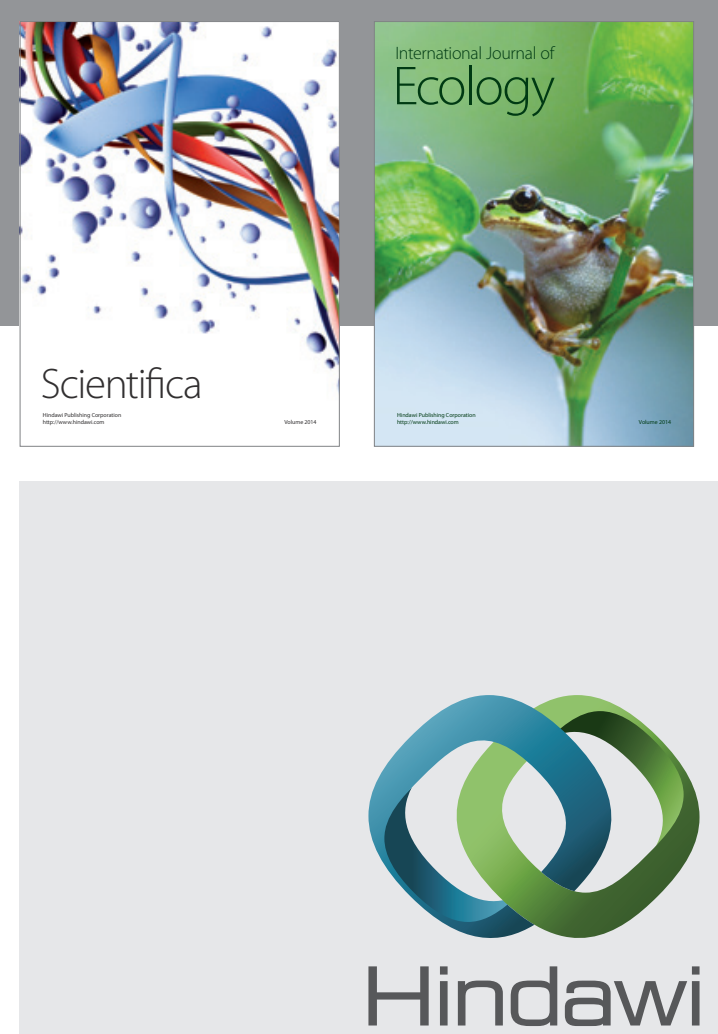

Submit your manuscripts at http://www.hindawi.com
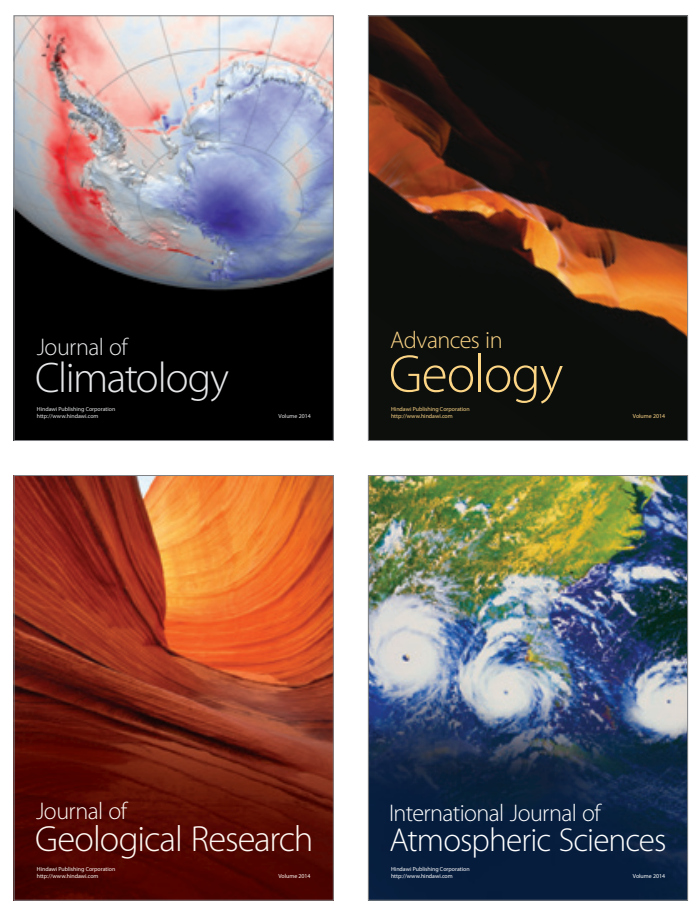
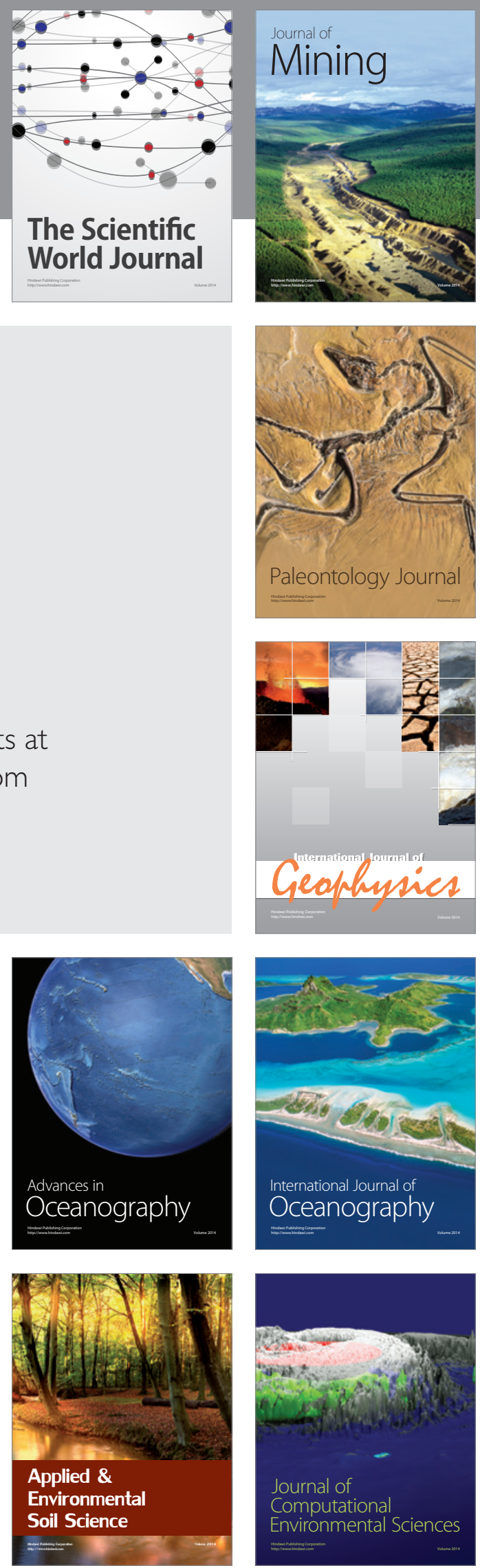